\title{
Review
}

\section{Targeted Delivery of Zinc Pyrithione to Skin Epithelia}

\author{
Sean E. Mangion 1,2,3, Amy M. Holmes ${ }^{1,2}$ and Michael S. Roberts 1,3,4,*(D) \\ 1 Therapeutics Research Centre, Basil Hetzel Institute for Translational Health Research, The Queen Elizabeth \\ Hospital, Woodville, SA 5011, Australia; sean.mangion@mymail.unisa.edu.au (S.E.M.); \\ amy.holmes@unisa.edu.au (A.M.H.) \\ 2 UniSA: Clinical and Health Sciences, University of South Australia, Adelaide, SA 5000, Australia \\ 3 Sydney Medical School, University of Sydney, Camperdown, NSW 2050, Australia \\ 4 Therapeutics Research Centre, Diamantina Institute, Translational Research Institute, University of \\ Queensland, Woolloongabba, QLD 4102, Australia \\ * Correspondence: m.roberts@uq.edu.au
}

Citation: Mangion, S.E.; Holmes, A.M.; Roberts, M.S. Targeted Delivery of Zinc Pyrithione to Skin Epithelia. Int. J. Mol. Sci. 2021, 22, 9730. https://doi.org/10.3390/ ijms22189730

Academic Editor: Philip W. Wertz

Received: 29 June 2021

Accepted: 30 August 2021

Published: 8 September 2021

Publisher's Note: MDPI stays neutral with regard to jurisdictional claims in published maps and institutional affiliations.

Copyright: (c) 2021 by the authors. Licensee MDPI, Basel, Switzerland. This article is an open access article distributed under the terms and conditions of the Creative Commons Attribution (CC BY) license (https:// creativecommons.org/licenses/by/ $4.0 /)$.

\begin{abstract}
Zinc pyrithione (ZnPT) is an anti-fungal drug delivered as a microparticle to skin epithelia. It is one of the most widely used ingredients worldwide in medicated shampoo for treating dandruff and seborrheic dermatitis (SD), a disorder with symptoms that include skin flaking, erythema and pruritus. SD is a multi-factorial disease driven by microbiol dysbiosis, primarily involving Malassezia yeast. Anti-fungal activity of ZnPT depends on the cutaneous availability of bioactive monomeric molecular species, occurring upon particle dissolution. The success of ZnPT as a topical therapeutic is underscored by the way it balances treatment efficacy with formulation safety. This review demonstrates how $\mathrm{ZnPT}$ achieves this balance, by integrating the current understanding of SD pathogenesis with an up-to-date analysis of ZnPT pharmacology, therapeutics and toxicology. ZnPT has anti-fungal activity with an average in vitro minimum inhibitory concentration of 10-15 ppm against the most abundant scalp skin Malassezia species (Malassezia globosa and Malassezia restrica). Efficacy is dependent on the targeted delivery of $\mathrm{ZnPT}$ to the skin sites where these yeasts reside, including the scalp surface and hair follicle infundibulum. Imaging and quantitative analysis tools have been fundamental for critically evaluating the therapeutic performance and safety of topical $\mathrm{ZnPT}$ formulations. Toxicologic investigations have focused on understanding the risk of local and systemic adverse effects following exposure from percutaneous penetration. Future research is expected to yield further advances in $\mathrm{ZnPT}$ formulations for $\mathrm{SD}$ and also include re-purposing towards a range of other dermatologic applications, which is likely to have significant clinical impact.
\end{abstract}

Keywords: seborrheic dermatitis; dandruff; Malassezia yeast; toxicology; fluorescent lifetime imaging microscopy

\section{Introduction}

Zinc pyrithione $(\mathrm{ZnPT})$ is a widely used anti-fungal ingredient in shampoo indicated for treating the symptoms of seborrheic dermatitis (SD) and dandruff. It has led a profitable history within the personal care industry, demonstrating how ongoing research efforts are improving topical formulation for the consumer market. Dandruff is estimated to affect $50 \%$ of the population [1], producing scalp flaking, pruritis and erythema [2,3], all of which can significantly impact daily living and psycho-social wellbeing $[4,5]$. In the more severe form it presents as $\mathrm{SD}$, a cutaneous disorder that affects approximately $1-3 \%$ of the adult population [6,7], resulting in more clinically significant scaling and irritation that can occur beyond the scalp (including the face, chest, back and flexural surfaces, Figure 1A) [8]. ZnPT was first synthesized during an anti-microbial screening program in the 1950s, originally established for agricultural purposes [9], and has remained a key commercial ingredient in the haircare industry since the 1960s after it was identified as a candidate anti-dandruff agent [10]. It is now the most popular anti-dandruff ingredient, listed in over 100 different topical products across multiple countries [11], at concentrations 
up to $2 \% w / v$ in rinse-off formulations [12]. While $\mathrm{ZnPT}$ can be incorporated into different formulations including lotions and tonics, shampoos are the most convenient and patient friendly. Therapeutic shampoos, such as those containing ZnPT, attract approximately 512 million USD of consumer expenditure annually in the Unites States alone [13].

A
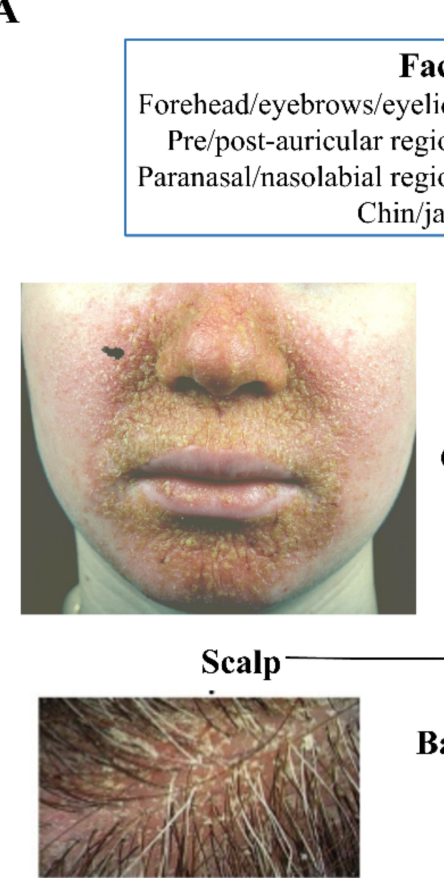

Mild/moderate disease: dandruff

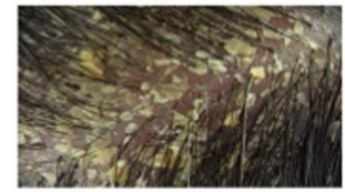

Severe disease: seborrheic dermatitis

\section{Host Factors}

Genetics and immunity

Age and gender

Diet and drugs

Underlying disease

Hormones and stress

Skin quality

(pH, sebum, hydration)

Grooming practices

Lifestyle factors

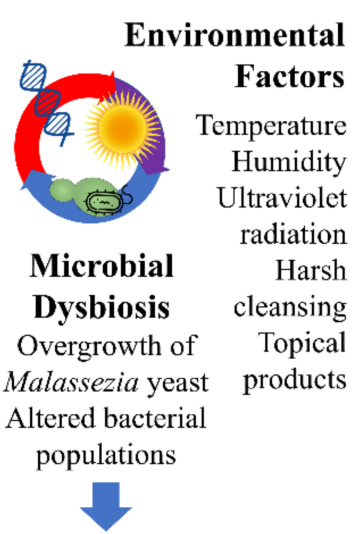

Irritant generation

Microbial/skin by-products:

- Oleic acid

- Malassezin

- Squalene peroxidase

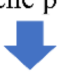

Stratum corneum permeation

Barrier compromise

Intercellular lipid

disruption

Inflammation

Altered enzyme activity

Seborrheic dermatitis

Flaking

Erythema

Itch

B
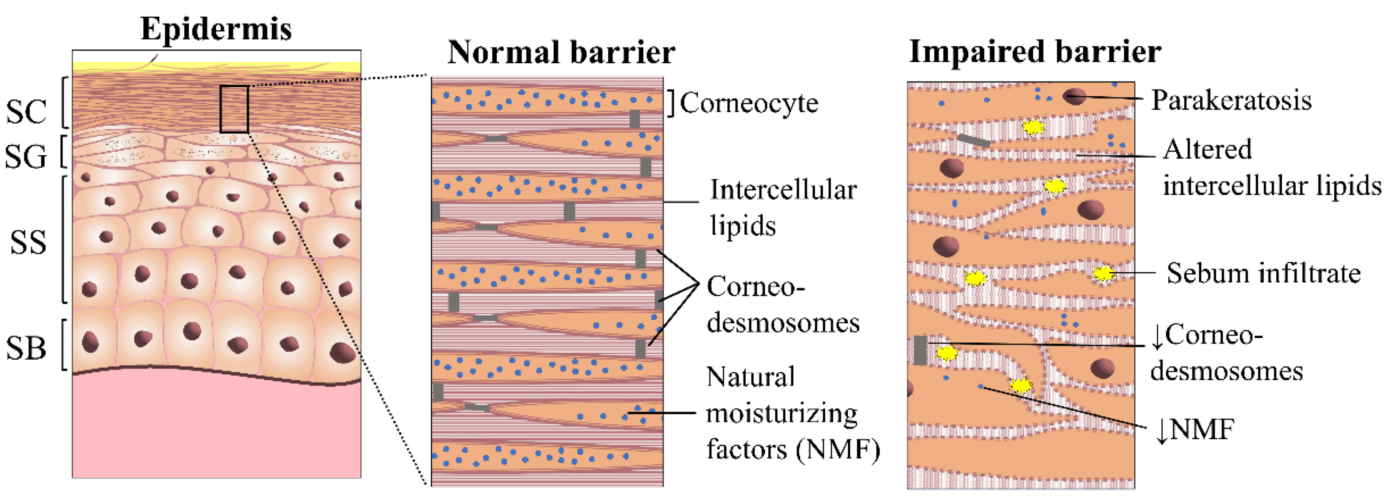

Figure 1. Seborrheic dermatitis and the skin. (A) Overview of the distribution pattern of seborrheic dermatitis with accompanying clinical photographs of selected regions. Veraldi et al. (2020), reproduced with permission [14] and Schwartz et al. (2015), reproduced with permission [15]. (B) Epidermal structure highlighting key features of the normal stratum corneum (SC) barrier and impaired barrier in seborrheic dermatitis. Proliferation of keratinocytes occurs exclusively from the stratum basale (SB). As these cells progressively travel upwards differentiation occurs in the stratum spinosum (SS) and granulosum (SG), resulting in the cornified cells of the SC, which are continuously shed from the skin surface by the process of desquamation. (C) Flow schematic demonstrating the interplay of microbial, host and environmental factors that drive seborrheic dermatitis pathogenesis. 
Anti-dandruff shampoos are one of the few over-the-counter topical products regulated both as a drug, where treating SD and dandruff is concerned, and cosmetic, due to the cleansing function of the shampoo [16]. ZnPT shampoos are continuously developed and strongly marketed, especially towards formulations that act faster and have multifunctional benefits. Numerous clinical studies demonstrate efficacy of ZnPT shampoo against the signs and symptoms of dandruff and SD [17-21]. This review will explore the interactions of $\mathrm{ZnPT}$ with skin epithelia, imperative for both therapeutic efficacy and safety.

\section{Skin Barrier Disturbance in Seborrheic Dermatitis}

Normal barrier integrity of the epidermis (Figure 1B) is regulated through the coordinated events of keratinocyte proliferation, differentiation, and desquamation. Electron microscopy of the SD affected stratum corneum has revealed disordered 'bricks and mortar' packing as well as excess lipid accumulation [22]. Skin contains lipid of two origins differing in both composition and purpose [23]. Lipids associated with the stratum corneum are synthesized during keratinocyte differentiation within intracellular lamellar bodies and upon extrusion create lipid bilayers with a highly regulated packing arrangement, ranging from fluid to crystalline [24]. The intercellular lipids represent the 'mortar' between the corneocyte 'bricks' and are essential for the epidermal water barrier and mechanical properties of the stratum corneum $[25,26]$. In SD the amounts of intercellular lipids are reduced and relative ratios are altered [27], supportive of changes to their packing arrangement.

The second type of lipid, sebum, originates from the exocrine secretions of the sebaceous glands and associated hair follicle. It is believed that sebum may participate in facilitating desquamation [28]. Clinically, 'dry' and 'oily' dandruff have been described [29], however the latter may simply represent the more severe form of SD with increased sebum a compensatory protective response of the skin to excess dryness. These sebaceous lipids have been identified using in vivo Raman spectroscopy in the lower stratum corneum in SD [20], where they likely are capable of disrupting the normal intercellular lipid bilayer structure and contributing to excessive desquamation [30].

In SD the stratum corneum is functionally compromised, demonstrated by elevated trans-epidermal water loss (TEWL) [29,31]. The weakened barrier is characterized by increased rates of keratinocyte proliferation and immature corneocytes reaching the skin surface [32], as evidenced by parakeratosis and reduced desmosome density [22,33]. Inflammation is also a key feature with elevated histamine [18] (responsible for itch) and proinflammatory cytokines such as interleukin(IL)-1 $\alpha$, IL-1 $\beta$, IL-2, IL-4, IL-6, IL-10, IL-12 and tumor necrosis factor- $\alpha$ [34-36]. Other epidermal changes include reduced expression of transglutaminase enzymes [37] involved in maturation of the cornified envelope [38] and reduced filaggrin proteins [37], which are precursors to natural moisturizing factors (NMFs) that contribute to skin flexibility $[20,37]$.

Current evidence indicates that epidermal changes in SD arise from a complex interplay of microbial, host and environmental factors (Figure 1C). Previous work has highlighted the importance of different aetiologic factors in SD including stratum corneum dysfunction [39], Malassezia yeast and sebum [40,41] as well as the wider microbiota, including bacteria [42]. Advances are continuing to be made in understanding the relative importance and inter-relations of each of these factors [43-46].

\section{Microbial Dysbiosis as a Key Target for Treatment}

Sebaceous skin sites, particularly on the scalp, provide a rich microenvironment for the colonization of bacteria, mainly Staphylococci and Propionibacterium species, as well as Malassezia yeast species [47]. The healthy cutaneous microbiome forms a symbiotic relationship with the host capable of supporting immunity [48], for example through competitive colonization analogous to the gut [49], upregulation of anti-microbial peptides [50] and promotion of compliment [51]. In dysbiosis the balance of micro-organisms is altered, driving skin disorders such as dandruff and SD [43,45]. 
As early as 1874 lipid-dependent Malessezia yeast were observed colonizing scaly lesions on the scalp [52]. Several lines of evidence followed linking Malassezia to SD symptomology. Firstly, Malessezia load correlated with condition severity [53], secondly, symptoms could be induced by Malessezia inoculation in guinea pig $[54,55]$ and thirdly, treatment occurred with a range of anti-fungal agents from zinc and selenium salts to azoles [54,56-60]. An excellent review of the early evidence is explored by Shuster [57].

Malessezia yeast have fastidious culture requirements and have had several nomenclature changes [61], with 18 species now recognized [62]. Malassezia globosa and Malessezia restricta predominate on the scalp [63,64], where they secrete lipases to breakdown sebum into fatty acids that can be assimilated for growth and survival $[65,66]$. A range of skin irritants have been implicated from the metabolic by-products of this breakdown, including oleic acid, malassezin, pityriacitrin, indolocarbazole and squalene peroxide [40,67-69]. These by-products can partition into the stratum corneum, disrupt normal lipid bilayer structure $[40,70]$ and trigger an irritation response that over time is believed to result in a pattern of structural (altered lipid and corneocyte packing), functional (elevated TEWL, altered $\mathrm{pH}$ and sebum secretion) and clinical features (flaking, erythema and itch) consistent with dandruff and SD [71,72]. IL-17, IL-4, IL-8 produced by immune cells such as neutrophils and lymphocytes, as well as keratinocytes themselves (via Toll-like receptor stimulation) are involved in inflammatory signaling that may link these events and lead to progression and maintenance of impaired barrier function [73].

Understanding the nature of microbial perturbations in SD is still an active area of research. It should be noted that studies of microbial load and SD severity have produced conflicting data in the past. While some reports demonstrated a correlation [53], others failed to demonstrate any relationship [74]. Fastidious culture requirements and the multidimensionality now recognized for SD pathogenesis are potential contributing factors. There are also contrary findings about the ability of Malassezia to assimilate unsaturated fatty acids for growth $[75,76]$, which has implications for elucidating the specific pathways underlying SD pathogenesis. Furthermore, while Malassezia yeast, particularly M. globosa and restricta likely play a key role, emerging data is also pointing towards involvement of bacteria, including an increase in Staphylococcus and a decrease in Propionibacterium species [43].

Although the picture of microbial dysbiosis is currently incomplete (particularly whether it is a cause or consequence of disease [77]), work thus far indicates that microbe biodiversity and abundance, influenced by host or intrinsic factors (e.g., age, gender, immunity and hormonal status) [78,79] and environmental or extrinsic factors (e.g., climate, physical activity, diet, grooming products or even face mask wearing as highlighted during the recent COVID-19 pandemic) $[14,80]$, are important in maintaining skin health or driving disease. The microbial component of disease has therefore been an important target in treatment with anti-fungal therapies such as the commercially popular ZnPT available over-the-counter. Indeed, histologic, biomolecular, and biophysical investigations demonstrate that clinical symptom improvement after treatment with ZnPT parallels restoration of stratum corneum structure and function, as well as the quality of emergent hair fibers [20,22,36,81-83].

\section{Zinc Pyrithione (ZnPT)}

\subsection{Zinc Pyrithione Structure and Physicochemical Properties}

$\mathrm{ZnPT}$ is a solid coordination complex of zinc with a molecular weight $=317.7 \mathrm{~g} / \mathrm{mol}$ and $\log \mathrm{P}=0.88$. These properties would ordinarily render a molecule highly permeable when applied on the skin, however skin permeation is limited for ZnPT due to low aqueous solubility of 5-15 ppm [12]. The rigid crystal lattice structure exists in the solid-state where two bridging oxygens form a pseudo-dimer between two ZnPT molecules (Figure 2A) [84]. Aside from limiting its permeability, the sparse water solubility also makes ZnPT ideal for deposition on the skin from rinse-off formulations, particularly in lipid rich regions such as the scalp. As ZnPT particles gradually dissolve the bioactive monomeric form (Figure 2B) 
is liberated, a structural analogue of the natural antibiotic aspergillic acid with anti-fungal activity against Malassezia yeast [85].

A

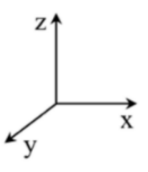

Solid state dimeric ZnPT

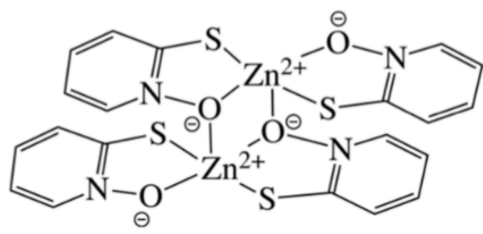

B Bioactive monomeric ZnPT<smiles></smiles>

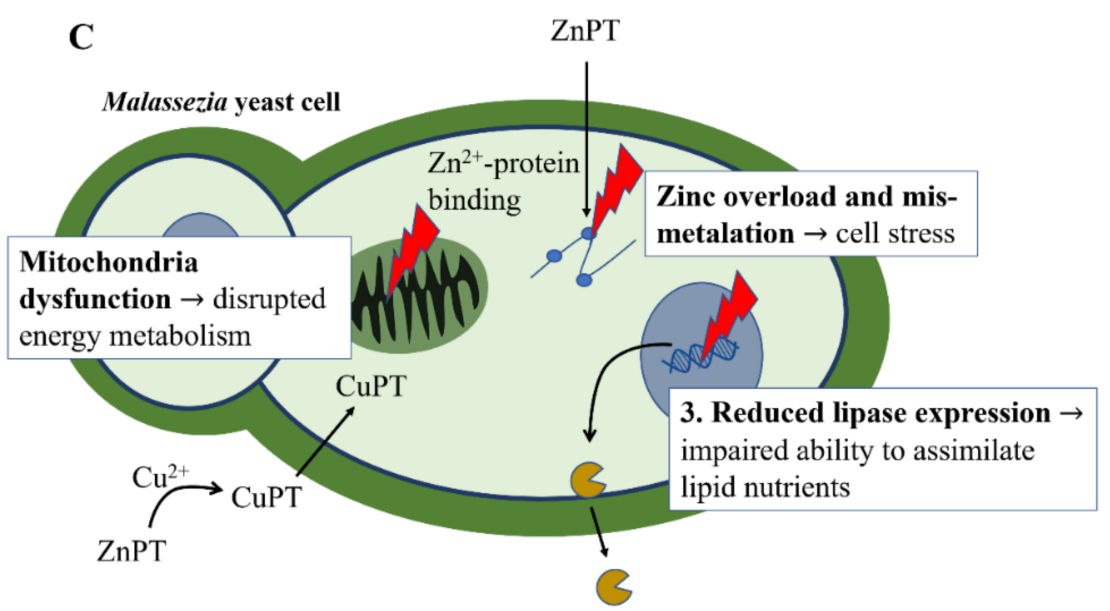

Figure 2. Zinc pyrithione molecular structure and anti-fungal mechanisms of action. (A) The dimeric structure of $\mathrm{ZnPT}$ in the solid state and (B) after dissolution into the bioactive form. (C) The three key actions of ZnPT on Malassezia yeast, resulting in zinc-induced cellular stress, disrupted energy metabolism and impaired ability to assimilate lipid nutrients for growth.

\subsection{Anti-Fungal Mechanisms of Action}

$\mathrm{ZnPT}$ has several mechanisms of action shown in Figure 2C. Firstly, as pyrithione is a known zinc ionophore, $\mathrm{ZnPT}$ causes elevated intracellular zinc levels in yeast cells $[85,86]$ to the extent that it results in mismetallation and cellular stress [87]. Secondly, endogenous levels of copper, which may be released during skin renewal or supplied by the immune system, are also involved in growth inhibition [88]. Anti-fungal effects are thought to occur via an extracellular transchelation reaction converting $\mathrm{ZnPT}$ into copper pyrithione, resulting in microbial intracellular copper influx [88,89]. This excess intracellular copper can then inactivate aconitase, which is an enzyme involved in fungal energy production within the mitochondria [90]. Studies have also demonstrated ZnPT inhibits the membrane transport of nutrients needed for yeast growth by inducing membrane depolarization [91-94]. Lastly, relatively recent evidence has demonstrated that in Malassezia restricta ZnPT can reduce lipase expression, critical for lipid breakdown, as well as downregulate gene expression for components of the Krebs Cycle (e.g., succinate dehydrogenase and citrate synthase) and electron transport chain (e.g., ATP synthase subunit) [86]. Together, these studies suggest $\mathrm{ZnPT}$ impairs the ability of fungal cells to assimilate and metabolize nutrients for growth, leading to growth inhibition. The relative contributions of each of these mechanisms to overall activity is not known, however the fact that $\mathrm{ZnPT}$ acts via multiple pathways likely explains why fungal resistance to this agent has not to our knowledge been reported (although resistance in Pseudomonas bacteria has been [95]).

\subsection{Pharmacological Response: Anti-Fungal Susceptibility Testing to Determine Target Doses for Topical Delivery}

The anti-fungal potency of ZnPT has been widely studied in vitro using the goldstandard broth microdilution susceptibility test [96]. The minimum inhibitory concentra- 
tion (MIC) is the lowest concentration of $\mathrm{ZnPT}$ that causes a decrease in yeast suspension turbidity, indicative of reduced fungal growth. Figure 3 presents a pooled analysis (mean \pm standard deviation) of anti-fungal MIC values from multiple studies against different Malassezia species [54,60,97-107].

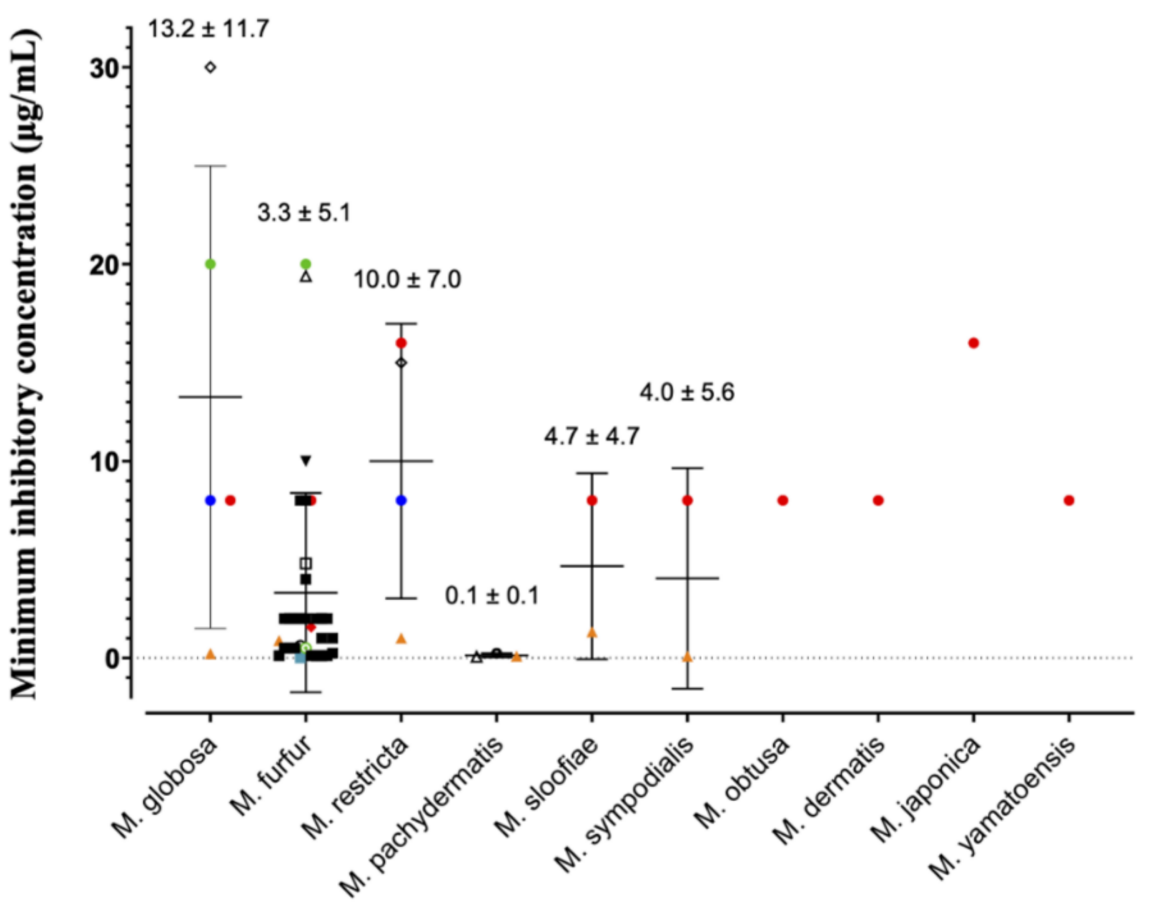

\section{Study}

- Onlom et al. 2014 [97]

- Leong et al. 2019 [98]

- Bulmer et al. 1999 [99]

_ Carrillo-Munoz et al. 2013 [100]

v Van Cutsem et al. 1990[54]

- Nenoff et al. 1994[60]

○ Rukayadi et al. 2007 [101]

- Rukayadi et al. 2012 [102]

- Squiquera et al. 1996 [103]

$\Delta$ Zieger et al. 2012 [104]

- Schimdt et al. 1996 [105]

ه Roques et al. 2006 [106]

- Kim et al. 2009 [107]

\section{Malassezia species}

Figure 3. Pooled analysis of minimum inhibitory concentrations for zinc pyrithione against various species of Malassezia yeast. Individual studies are coded in the legend. Where the MIC of the original dataset was reported as a range, only the upper limit was included as a conservative approach to analysis. Data is presented as mean \pm standard deviation.

Prior work suggests that Malassezia globosa and restrica may be more susceptible compared to Malassezia fufur [98], however the pooled analysis presented here demonstrates the opposite trend. Intra-species MIC values range significantly for most species, for example from $0.21 \mu \mathrm{g} / \mathrm{mL}$ [100] to $30 \mu \mathrm{g} / \mathrm{mL}$ [106] for Malassezia globosa. Different strains and assay methods are likely contributors. The ZnPT preparation is also important for anti-fungal bioavailability, as particles are more soluble in certain solvents such as dimethyl sulfoxide (DMSO) $(30 \mathrm{mg} / \mathrm{mL})$ and ethanol $(0.31 \mathrm{mg} / \mathrm{mL})$ compared to water and saline $(0.015 \mathrm{mg} / \mathrm{mL})[12,108]$. This can have a significant effect on MIC value, for instance when DMSO is substituted for distilled water in two similar studies $[97,98]$ with the same strain of Malassezia fufur (CBS 1878) the MIC increases 2.5-fold from $8 \mu \mathrm{g} / \mathrm{mL}$ to $20 \mu \mathrm{g} / \mathrm{mL}$. Studies have also demonstrated no difference in fungal susceptibility of Malassezia globosa from patients who use and do not regularly use anti-fungal shampoo, which is an important consideration for continued maintenance therapy [109]. Overall, our analysis reveals that for the two most important fungal species in dandruff and SD, Malassezia globosa and Malassezia restrica $[63,64]$, average effective anti-fungal concentrations for topical delivery should be approximately $10-15 \mu \mathrm{g} / \mathrm{mL}$.

A noteworthy limitation of the broth microdilution method for establishing an effective anti-fungal dose is that it is unable to capture the host-microbe interactions, which occur in vivo, that may modify fungal susceptibility to ZnPT. Further investigations using methods should be performed that can (1) better replicate conditions of the scalp microenvironment in a controllable system (that way removing the confounding variables that may occur in vivo) and (2) better replicate the exposure and contact that occurs after topical administration of ZnPT. A range of in vitro and in vivo methods for further exploring 
host-microbe interactions has recently been reviewed [110]. One interesting method that has been reported separately involves inoculation of hair strands in agar after simulated shampoo washing and rinsing [111].

There is also access to more sensitive yeast identification tools such as PCR determination, based on internal transcribed spacer regions of ribosomal DNA [112], which has been used to follow yeast loads over 7 days [109]. One limitation of this approach (compared to culture-based methods) is that it is not able to differentiate between live and dead yeast. A combination of culture-based and molecular methods and more advanced techniques such as matrix-assisted laser desorption ionization time-flight mass spectrometry (MALDITOFMS) [113] are likely to provide a complementary balance of sensitivity and specificity required for future analyses in the field.

\subsection{Deposition of ZnPT on Human Skin Epithelia}

Deposition of ZnPT is important because the particles retained on the scalp following shampoo rinsing have the longest exposure time and are the main sources of anti-fungal action $[114,115]$. For targeted anti-fungal delivery, deposition should mirror the spatial distribution of Malassezia yeast on the skin. There are two locations to consider, including the hair follicles and the interfollicular skin surface.

Hair follicles are invaginations of the skin surface that support the hair in various stages of growth. The skin contains 3 distinct types of follicles, which vary in morphological characteristics and distribution (Figure 4A) [116]. Vellus follicles are the smallest, contain unpigmented hair and are found body wide, although predominate before puberty. Terminal follicles are significantly deeper, contain pigmented hairs and predominate at sites such as the scalp, axilla, pubic area, and the legs. Sebaceous follicles are moderately sized and contain numerous sebaceous glands, predominating on the face, back and chest. Terminal hair follicles are the most relevant to consider for scalp SD, while sebaceous follicles are the most relevant for SD occurring on the face, chest and back.

Buds of Malassezia yeast have been observed superficially in clumps on desquamating corneocytes [117] and interspersed between corneocyte layers of the stratum corneum, forming a particularly dense load in seborrheic dermatitis [22,118] (Figure 4B). Malassezia yeast have also been directly observed accumulating at follicle sites on the scalp (Figure 4C,D) [119]. While precise data on the follicle distribution of Malassezia is missing [120], the funnel shaped infundibulum at the uppermost region is an ideal site to act as a microbial reservoir as it provides protection against skin sloughing and is irrigated with sebaceous lipids. The infundibulum has also been postulated to have a more permeable stratum corneum with a higher density of antigen presenting cells in the lower region [121,122] which, if correct, could mean could that infundibular skin is at increased susceptibility to Malassezia-derived irritants and the subsequent inflammatory cascade. As well yeast, approximately $25 \%$ of skin bacteria in the human forearm are localized within the follicles [123].

The equilibria dynamics of $\mathrm{ZnPT}$ in the product packaging and once deposited onto the skin are important for governing anti-fungal bioactivity (Figure 5) [9,85]. ZnPT particles (solid state dimer) exist in an equilibrium with the dissolved state ZnPT (monomer), the latter of which represents the bioactive species. Activity can be lost if the coordination complex dissociates further into its zinc and pyrithione moieties. Delivery should be optimized to prevent active-complex dissociation and bioavailability has been improved through the addition of zinc layered materials such as zinc carbonate. This strategy provides a sustained source of common zinc ions that act to shift the equilibrium towards the bioactive complex, preventing dissociation in both the bottle and once deposited onto the skin. Shampoos containing additional zinc display enhanced anti-fungal activity in vitro against Malassezia globosa, as well as improved anti-dandruff efficacy in vivo [56]. 


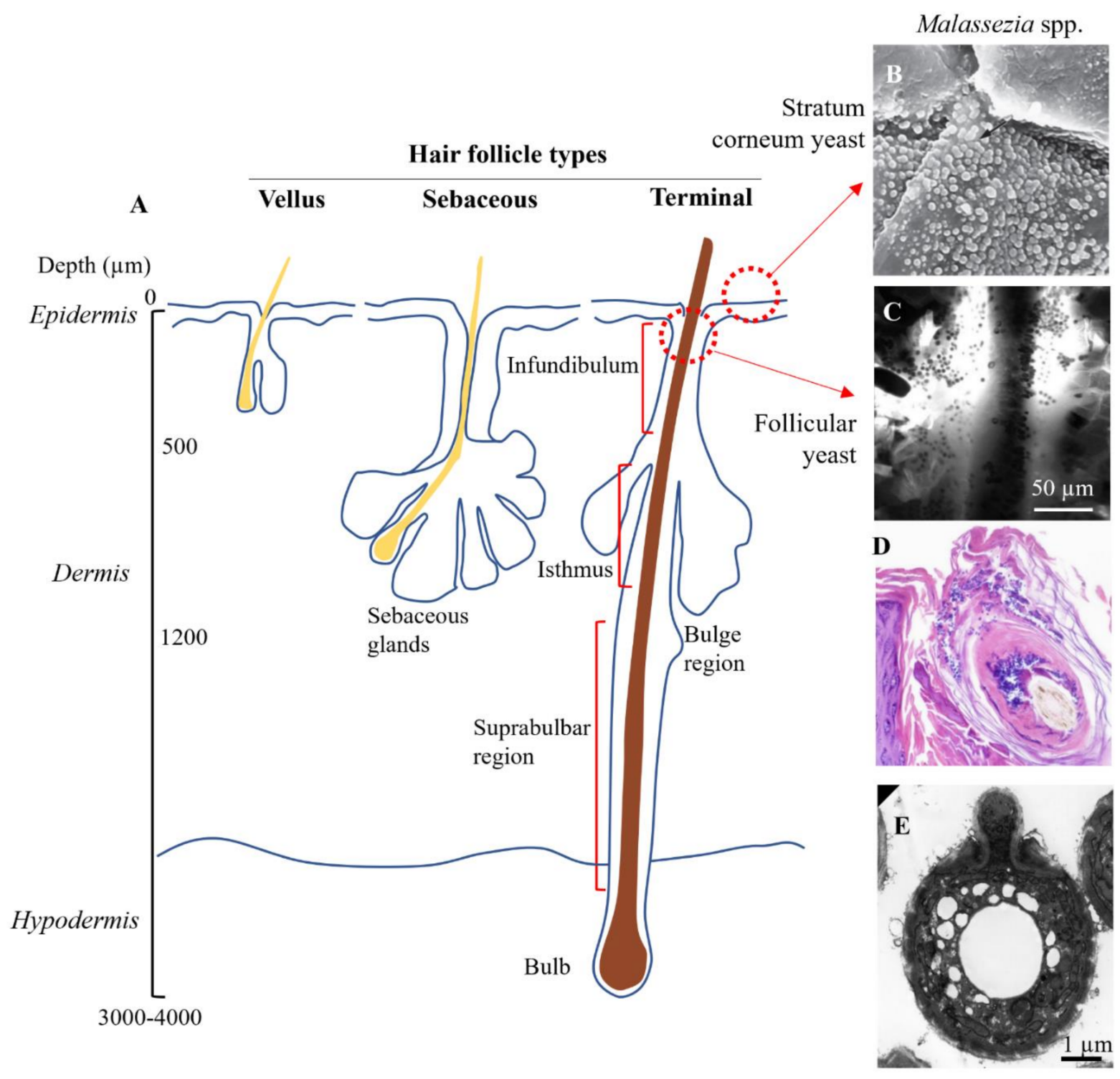

Figure 4. Target sites for topical zinc pyrithione. (A) Schematic showing anatomy of the three different types of hair follicle. (B) Surface colonization of Malassezia yeast ( $\times 2700$ magnification). Piérard et al. (2006), reproduced with permission [117]. (C) Yeast colonization in the infundibulum imaged using in vivo confocal microscopy. Meyer et al. (2005), reproduced with permission [119]. (D) Yeast congregating and spreading within epithelial cells of the hair follicle $(\times 20$ magnification), reproduced from [124] in accordance with StatPearls Publishing LLC Creative Commons Attribution 4.0 International License. (E) Electron micrograph of Malassezia yeast isolated from the skin. Guého-Kellermann, et al. (2011), reproduced with permission [125]. 

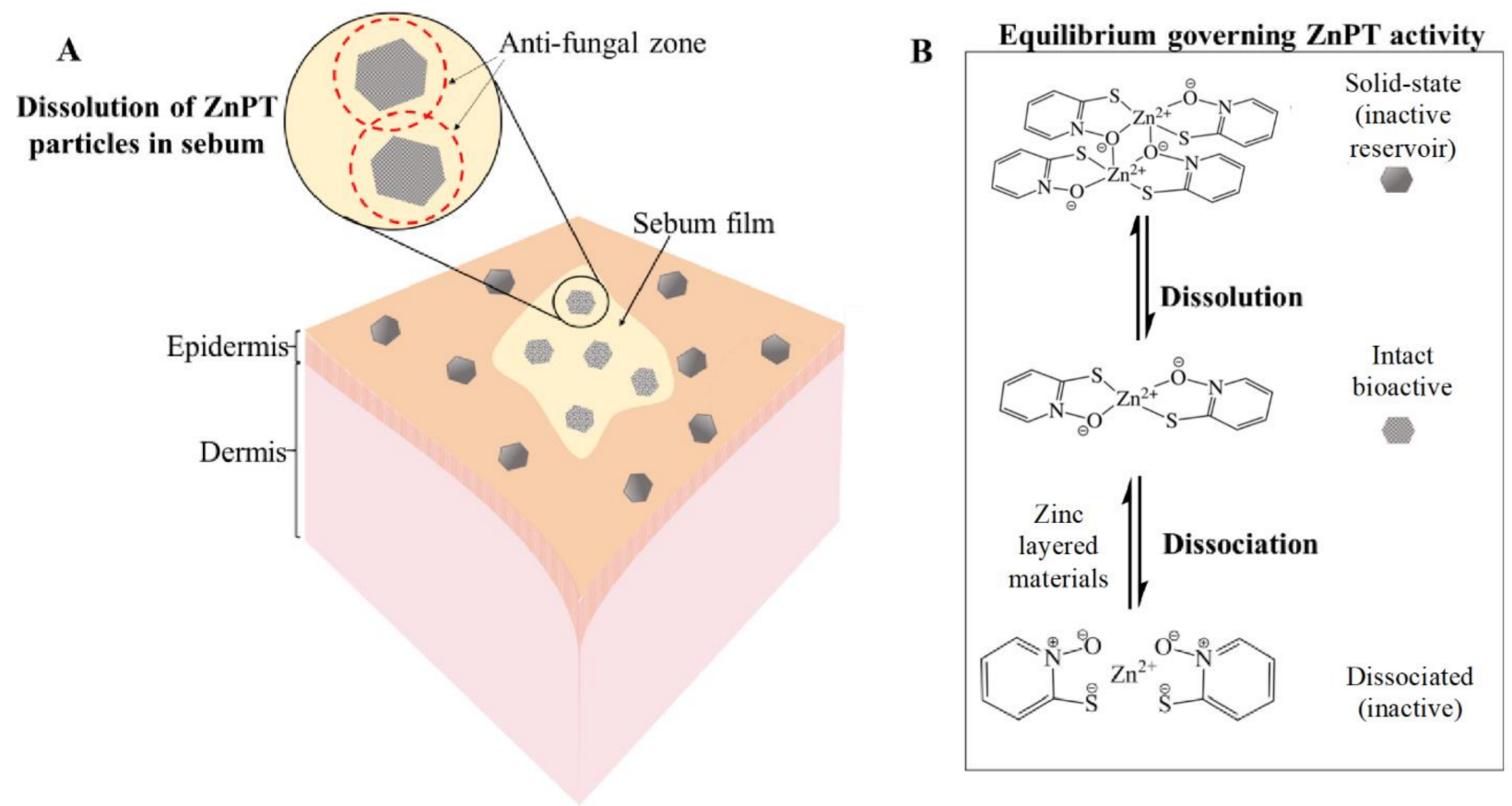

Figure 5. Zinc pyrithione deposition on the skin. (A) Solid-state ZnPT particle dissolution occurring in a film of sebum covering the skin surface releasing bioactive $\mathrm{ZnPT}$. (B) Equilibria governing anti-fungal delivery to the follicles with zinc layered materials boosting levels of bioactive species.

\section{Skin Imaging Methods to Evaluate the Spatial Delivery of ZnPT}

A range of complementary imaging methods have been used over the past 50 years for measuring the delivery of ZnPT after topical application to the skin [56,85,115,126-132]. Each modality carries advantages and disadvantages summarized in Table 1. Factors such as study design (in vivo realistic exposure or ex vivo controlled dosing), sample preparation (physical or optical sectioning) and type of skin (human or animal) are potential confounders in interpreting the results of imaging data.

Table 1. Comparison of skin imaging methods for assessing zinc pyrithione topical delivery.

\begin{tabular}{|c|c|c|c|}
\hline Imaging Method & Advantages & Disadvantages & Key Findings \\
\hline $\begin{array}{c}\text { Autoradiography } \\
{[126,127]}\end{array}$ & $\begin{array}{l}\text { Chemical specificity and } \\
\text { sensitivity } \\
\text { Acquisition of both } \\
\text { qualitative and quantitative } \\
\text { data }\end{array}$ & $\begin{array}{l}\text { Radiolabelling can modify } \\
\text { chemical properties } \\
\text { important for delivery } \\
\text { Expensive } \\
\text { Requires careful handling } \\
\text { and preparation } \\
\text { Safety (exposure to } \\
\text { radiation) }\end{array}$ & $\begin{array}{l}\text { Localisation of ZnPT around hair } \\
\text { follicle opening and no } \\
\text { penetration into dermal layer } \\
\text { [126] } \\
\text { Lateral micro-transport is } \\
\text { formulation dependent [127] }\end{array}$ \\
\hline $\begin{array}{c}\text { Confocal Microscopy } \\
{[56,115]}\end{array}$ & $\begin{array}{c}\text { High resolution } \\
\text { Ability to optically section } \\
\text { skin } \\
\text { Pseudo-quantification of } \\
\text { delivery } \\
\text { Non-invasive, therefore } \\
\text { ideal to be performed } \\
\text { in vivo }\end{array}$ & $\begin{array}{c}\text { Resolution drops after } \\
\text { approximately } 150-200 \mu \mathrm{m} \\
\text { through tissue } \\
\text { Low chemical specificity in } \\
\text { reflectance mode }\end{array}$ & $\begin{array}{l}\text { Follicular delivery is formulation } \\
\text { dependant, with signal detection } \\
\text { greatest in upper infundibulum } \\
\text { (upper 0-40 } \mu \mathrm{m} \text { ) [115] }\end{array}$ \\
\hline
\end{tabular}


Table 1. Cont

\begin{tabular}{|c|c|c|c|}
\hline Imaging Method & Advantages & Disadvantages & Key Findings \\
\hline $\begin{array}{c}\text { Raman Microscopy } \\
{[128,129]}\end{array}$ & $\begin{array}{l}\text { Chemical specificity } \\
\text { Ability to optically section } \\
\text { skin, therefore ideal for } \\
\text { in vivo use }\end{array}$ & $\begin{array}{l}\text { Optical sectioning limited to } \\
\text { maximum } 100 \mu \mathrm{m} \text { depth } \\
\text { Spectral interpretation can } \\
\text { be difficult }\end{array}$ & $\begin{array}{l}\text { Follicular delivery limited to } \\
\text { upper follicle }(20 \mu \mathrm{m}) \text { in porcine } \\
\text { skin. Plate morphology of } \\
\text { particles observable on scalp } \\
\text { surface. }\end{array}$ \\
\hline $\begin{array}{l}\text { Scanning Electron } \\
\text { Microscopy } \\
\text { (SEM) }[130,131]\end{array}$ & $\begin{array}{l}\text { High resolution } \\
\text { Enables assessment of } \\
\text { particle morphology } \\
\text { Combined with X-ray } \\
\text { spectroscopy to enable } \\
\text { chemical specificity }\end{array}$ & $\begin{array}{c}\text { Expensive } \\
\text { Sample preparation } \\
\text { Time consuming } \\
\text { Only suitable for ex vivo } \\
\text { tissue or indirect tape strips }\end{array}$ & $\begin{array}{c}2 \mu \mathrm{m} \text { plate morphology of } \\
\text { particles on scalp surface [130] }\end{array}$ \\
\hline $\begin{array}{c}\text { Fluorescent Lifetime } \\
\text { Imaging Microscopy (FLIM) } \\
\text { [131] }\end{array}$ & $\begin{array}{l}\text { Chemical specificity and } \\
\text { sensitivity } \\
\text { High resolution } \\
\text { Ability to optically section } \\
\text { skin } \\
\text { Non-invasive technique can } \\
\text { be performed in vivo }\end{array}$ & $\begin{array}{c}\text { Expensive } \\
\text { Acquisition time for } \\
\text { sufficient photon count to } \\
\text { produce image (times are } \\
\text { improving) } \\
\text { Histological tissue } \\
\text { sectioning may not provide } \\
\text { representative view of } \\
\text { delivery }\end{array}$ & $\begin{array}{l}\text { Delivery of } \mathrm{ZnPT} \text { in aqueous } \\
\text { suspension at up to } 200 \mu \mathrm{m} \text { in } \\
\text { hair follicle. }\end{array}$ \\
\hline
\end{tabular}

\subsection{Autoradiography}

Autoradiography was the earliest method of imaging ZnPT on skin [126]. Radiographs of lateral cryosections of guinea pig skin dosed with $\left.{ }^{35} \mathrm{~S}\right]$-labelled ZnPT shampoo $(1.7 \% w / v)$ showed accumulation around the follicle entrance with no dermal penetration (Figure 6A). Similar principles have been used recently in quantitative radioluminographic imaging to calculate kinetics of ZnPT micro-transport across dermatomed human skin (Figure 6B) [127]. Results show a greater lateral diffusivity of ZnPT in $1 \% w / w$ body wash $\left(9.2 \times 10^{-9} \mathrm{~cm}^{2} / \mathrm{s}\right)$ compared to $1 \% w / v$ carboxymethylcellulose formulation $\left(0.94 \times 1010^{-9} \mathrm{~cm}^{2} / \mathrm{s}\right)$. These formulation effects are an important factor for anti-fungal bioavailability of $\mathrm{ZnPT}$ to target structures in the skin.

\subsection{Confocal Microscopy}

Confocal microscopy is a safe and non-invasive tool that has been used in vivo to image $\mathrm{ZnPT}$ on skin $[56,115]$. Adjusting the focal plane in tissue allows optical sectioning after lather and rinsing of $\mathrm{ZnPT}$ shampoo. Reflectance confocal imaging shows $\mathrm{ZnPT}$ delivery to the follicular infundibulum [115] (Figure 7A) with greater resolution compared to initial radioisotope work (Figure 6A) [126]. The depth profile for delivery derived from pixel counting algorithms demonstrates that deposition predominates within the upper $40 \mu \mathrm{m}$ of the infundibulum (Figure 7B) [115]. While there is signal detected up to $150 \mu \mathrm{m}$, a key disadvantage of this technique is that it lacks chemical specificity. Therefore, it is possible for skin debris and other ingredients deposited on the scalp, such as zinc carbamate [56,130], to be detected in the reflectance mode where there is no way of discriminating these signals from $\mathrm{ZnPT}$. 
A

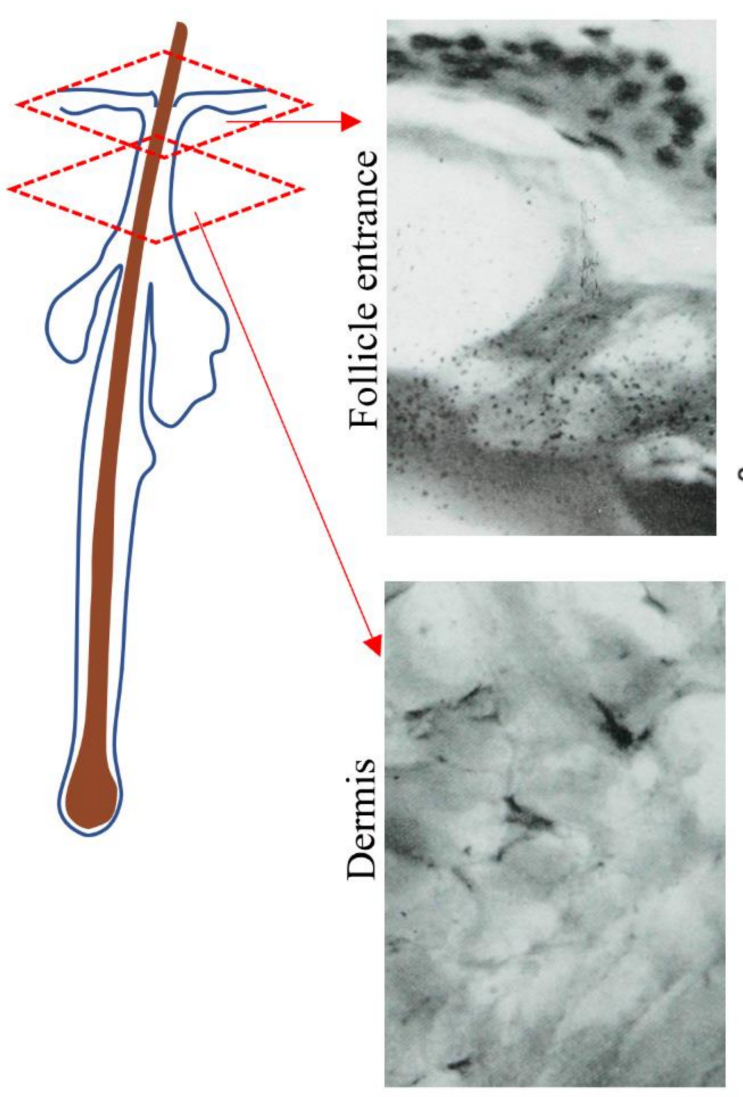

B
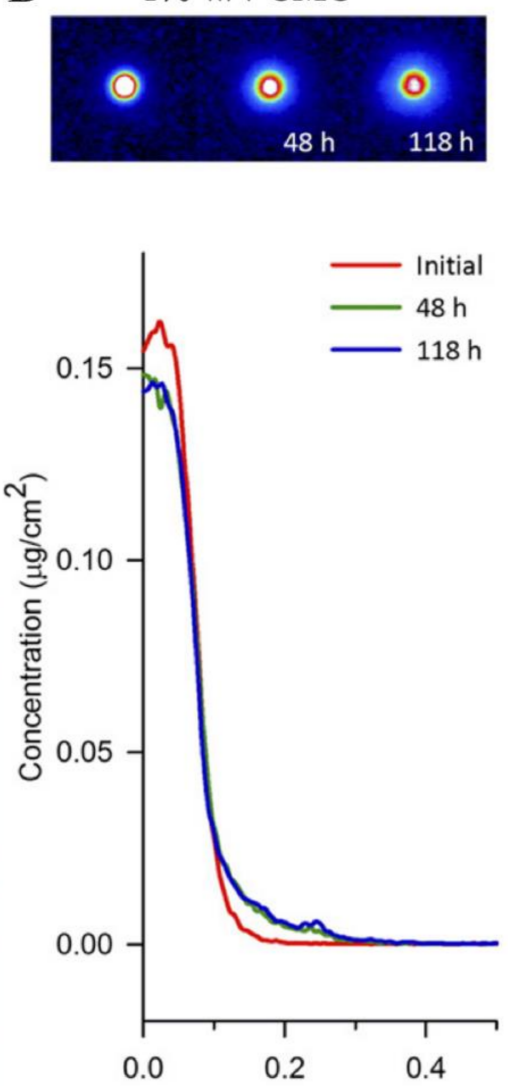

$1 \% \mathrm{w} / \mathrm{w}$ Body wash

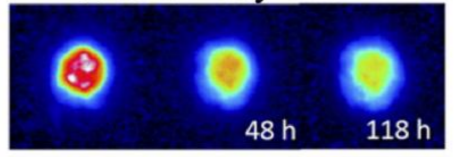

$0.15-118 \mathrm{~h}$

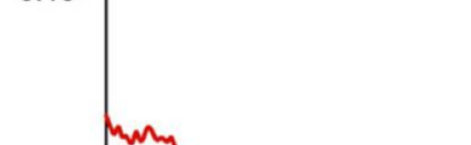

0.10

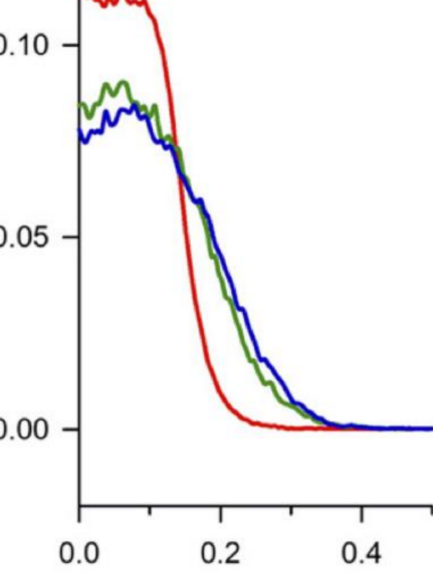

Radial Distance from Center $(\mathrm{cm})$

Figure 6. Autoradiography for assessing zinc pyrithione topical delivery. (A) Radiograph of lateral cryosection demonstrating moderate grain density of $\mathrm{ZnPT}$ particles localized around the entrance of a follicle (upper panel), but not in the dermis (lower panel) of guinea pig skin ( $\times 500$ objective). Rutherford et al. (1969), reproduced with permission [126]. (B) False-colored quantitative radioluminographic images (upper panels) with accompanying average concentrationdistance profiles (lower panels) for initial and subsequent ZnPT dose distributions on human skin, demonstrating greater lateral micro-transport of $\mathrm{ZnPT}$ with time in $1 \%$ body wash $w / w$ (right) compared to aqueous carrier containing $1 \% w / v$ carboxymethylcellulose (CMC, left). Rush et al. (2015), reproduced with permission [127]. 
A Confocal Microscopy

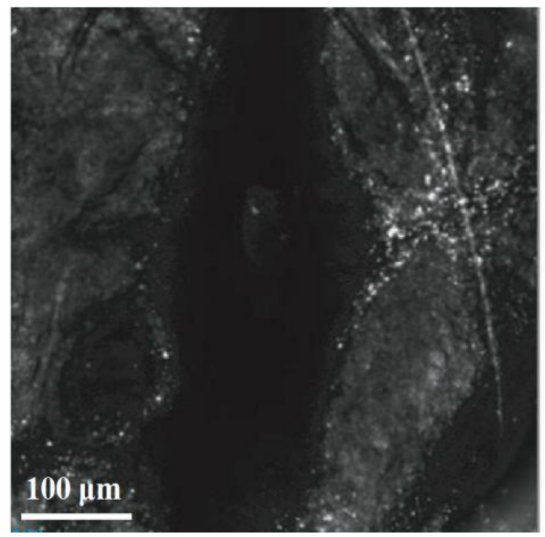

B

ZnPT Follicular Delivery Profile

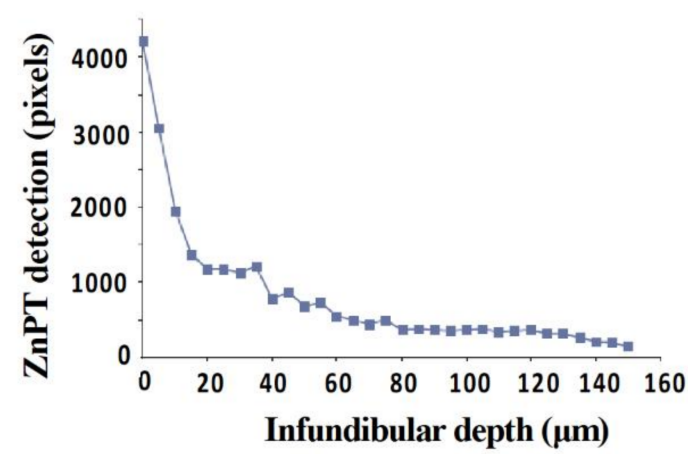

C

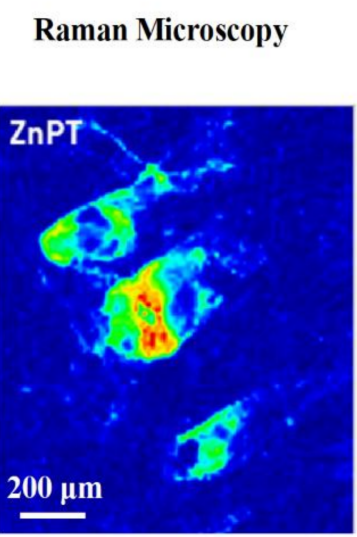

Scanning Electron Microscopy

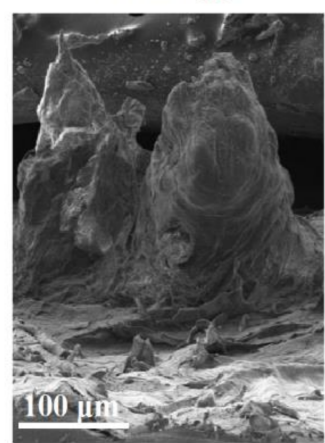

D

\section{Stimulated Raman Spectroscopy}

(SRS) Microscopy

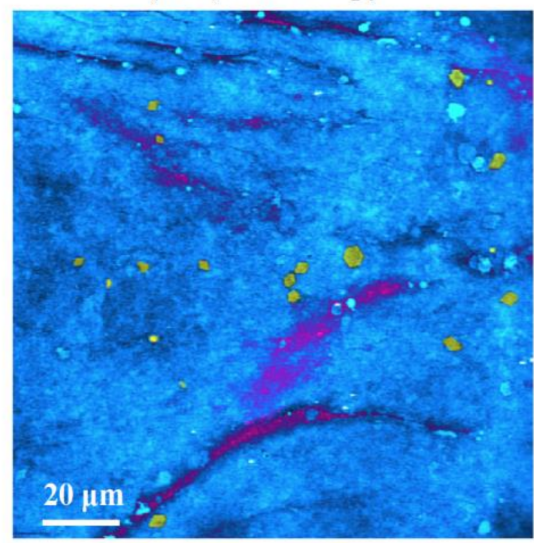

E

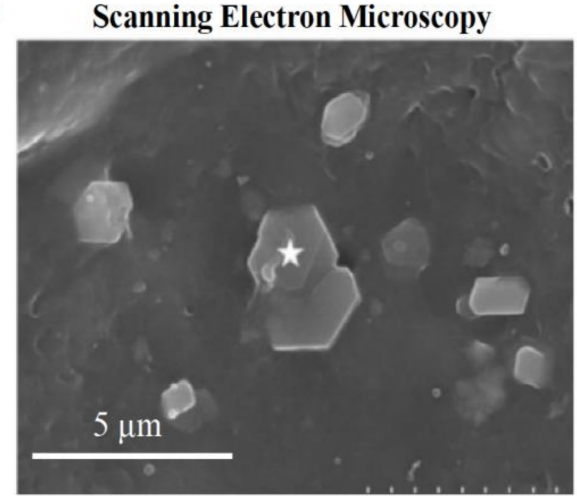

F

Dispersive X-Ray Spectroscopy

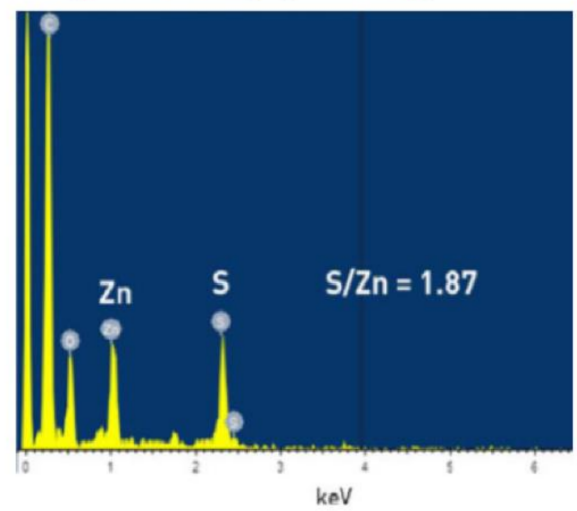

Figure 7. Reflectance and scattering methods for assessing zinc pyrithione topical delivery. (A) In vivo reflectance confocal image $(40 \mu \mathrm{m})$ of human hair follicle showing particle deposition and (B) accompanying pixel-depth profile. Schwartz et al. (2011), reproduced with permission [115]. (C) Raman microscopy image, intensity weighted by color (red—high, blue-low), of an ex vivo cyano-acrylate hair follicle biopsy with accompanying scanning electron microscopy (SEM) image of cyano-acrylate follicular cast. Chen et al. (2017), reproduced with permission [128]. (D) Stimulated Raman Spectroscopy (SRS) microscopy image of ZnPT (yellow particles) and climbazole (magenta) on the surface of ex vivo porcine skin. Garrett et al. (2017), reproduced with permission [129]. (E) SEM image of tape stripped skin from scalp washed with ZnPT shampoo with (F) accompanying dispersive X-ray spectra (from the star marked region) confirming its chemical identity. Chen et al. (2018), reproduced with permission [130]. 


\subsection{Raman Spectroscopy}

Chemical specificity is an advantage of Raman microscopy, which relies on detecting the Raman scattering of a sample after infrared excitation to determine molecular vibrational modes [133]. ZnPT can be discriminated based on signals from chemical motifs not present in human skin or other ingredients [134]. Raman imaging has been used ex vivo on human cyanoacrylate glue casts collected after shampoo application to visualize the follicular deposition of ZnPT with relative signal intensity mapping (Figure 7C) [128]. While traditional Raman offers low spatial resolution, Stimulated Raman Scattering (SRS) microscopy improves resolution by coherent excitation [135] and has been used on porcine skin to show ZnPT delivery on the scalp surface with very good visualization of particle morphology (Figure 7D) and follicular delivery up to 10-20 $\mu \mathrm{m}$ [129].

The difference in $\mathrm{ZnPT}$ follicular delivery reported using Raman [129] compared to reflectance confocal microscopy [115] could be explained by the weaker detection ability of Raman at greater tissue depth, formulation factors specific to the shampoo, or differences in ex vivo porcine skin and in vivo human skin-although if this was the case greater delivery might be expected with the larger follicles of porcine skin [136]. Lastly, the discrepancy in follicular delivery may be due to interference in reflectance confocal images occurring as a result of low chemical specificity.

\subsection{Scanning Electron Microscopy}

Scanning electron microscopy (SEM) enables high resolution and magnification of $\mathrm{ZnPT}$, especially suited for assessing morphology of particles deposited on the scalp (Figure 7E). Coupling SEM with dispersive X-ray spectroscopy of tape strips from scalp skin washed with ZnPT shampoo allows separate identification of ZnPT and zinc carbamate particles based on characteristic signals from zinc and sulfur (Figure 7F) [130]. This method has been useful for investigating the influence of particle size and shape on ZnPT retention, demonstrating that $2 \mu \mathrm{m}$ plate shaped particles are optimal, at least for scalp surface delivery, which is consistent with earlier reports [85].

\subsection{Fluorescence Lifetime Imaging Microscopy}

The imaging methods discussed thus far have been primarily limited either by spatial resolution, chemical specificity, or a combination of both. We have previously reported and characterized the optical properties of $\mathrm{ZnPT}$ using both single-photon and two-photon laser excitation [131], which has opened up the opportunity of using new imaging methods for sensitive and specific ZnPT skin delivery assessment both ex vivo and in vivo. Fluorescent lifetime imaging microscopy (FLIM) is an ideal tool that can resolve images both spectrally and by fluorophore lifetime, thereby enabling high chemical sensitivity [137].

With the methods previously described [131], we have used multiphoton microscopy (MPM, Figure 8A) combined with FLIM (Figure 8B) to map ZnPT delivery within the hair follicles of human skin [132]. ZinPyr-1 is a fluorescent probe used to detect labile zinc within tissue and it has previously been applied to observe relative increases in labile zinc within skin after topical application of zinc species [138-140]. Staining with ZinPyr-1, enables visualization of increased labile zinc within the skin while the inherent luminescence of $\mathrm{ZnPT}$ enables visualization of particle deposition. Using MPM-FLIM we observed delivery of ZnPT from a $2 \% w / v$ aqueous suspension up to approximately $200 \mu \mathrm{m}$ within the hair follicle. Imaging with FLIM will be important in future studies to explore delivery from commercial $\mathrm{ZnPT}$ formulations. 
A

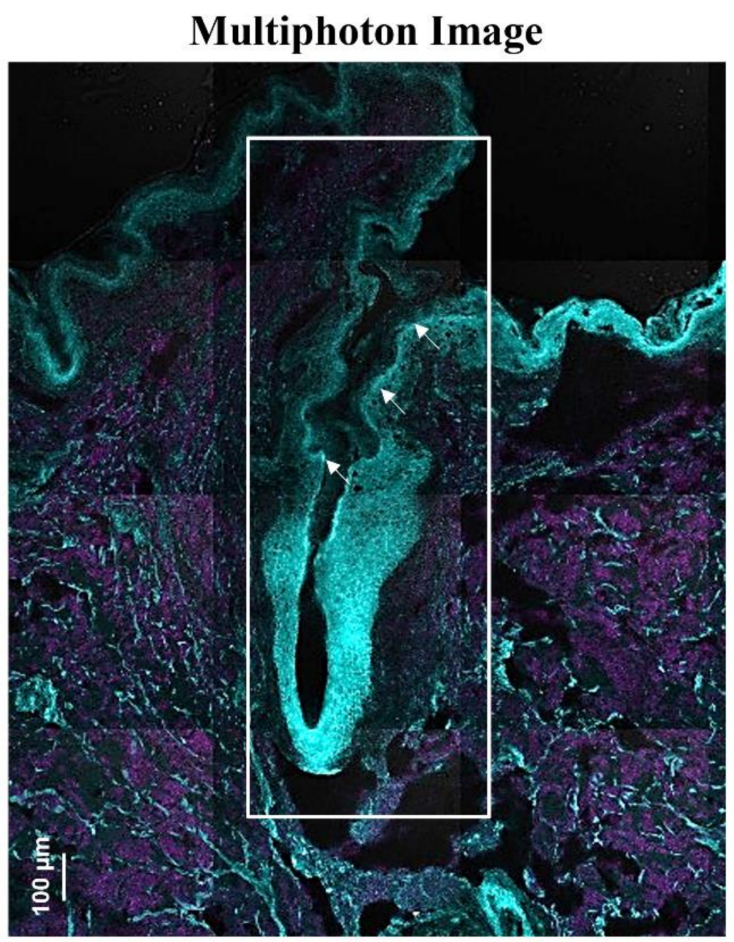

B

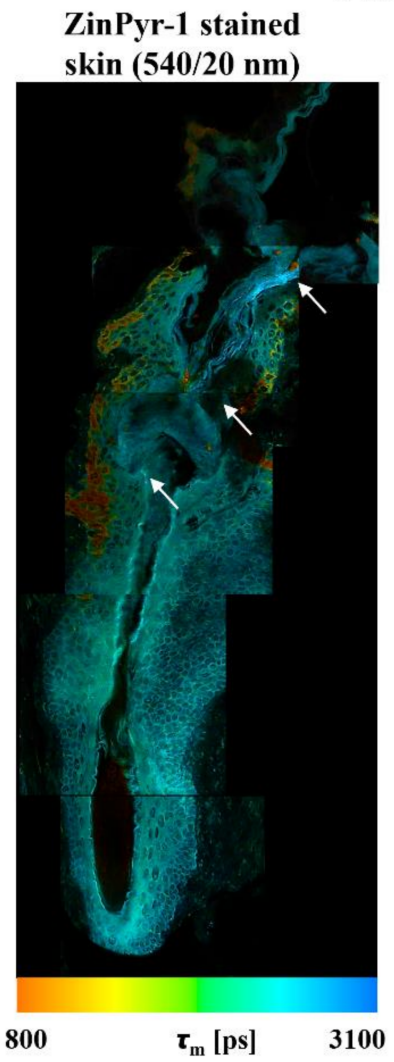

FLIM Image

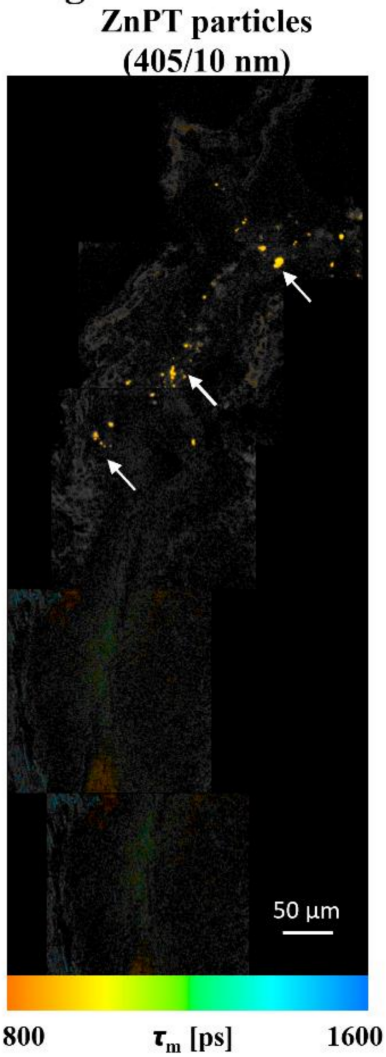

Figure 8. Fluorescence lifetime imaging microscopy (FLIM) for assessing zinc pyrithione follicular delivery to human skin. Skin was dosed with $2 \% w / v$ aqueous ZnPT suspension and cryosectioned to $20 \mu \mathrm{m}$. (A) ZinPyr-1 stained skin imaged with multiphoton microscopy (two-photon excitation, cyan region $\lambda_{\mathrm{ex}}=800 \mathrm{~nm}, \lambda_{\mathrm{em}}=370-420 \mathrm{~nm}$; single-photon excitation, magenta region $\lambda_{\mathrm{ex}}=488 \mathrm{~nm}, \lambda_{\mathrm{em}}=520-560 \mathrm{~nm}$ ). (B) FLIM image pseudo-coloured to average time-weighted lifetime, $\tau$ [picoseconds] (two-photon excitation; $\lambda_{\mathrm{ex}}=740 \mathrm{~nm}$; emission detected using two bandpass filters indicated). Arrows mark ZnPT particle deposition.

\subsection{Radiolabeling Studies to Quantify Exposure}

Imaging studies provide spatial information and topical application, however rarely can provide accurate quantitative data on delivery amounts. Quantification of dose can be performed with a range of chromatography, spectroscopy and radiolabeling methods highlighted in Table $2[12,115,128,130,141-144]$. An important consideration for formulation optimization is that the same quantitative approach must be followed when comparing delivery between formulations, as each analysis method will have different levels of accuracy and precision. 
Table 2. Quantification of zinc pyrithione delivery to skin.

\begin{tabular}{|c|c|c|c|c|c|c|c|c|c|}
\hline \multirow{2}{*}{ Analytic Method } & \multirow{2}{*}{ Skin } & \multirow{2}{*}{ Formulation } & \multirow{2}{*}{ Dose } & \multirow{2}{*}{ Exposure Time } & \multirow{2}{*}{$\begin{array}{l}\text { Limit of Detection/Specific } \\
\text { Activity }\end{array}$} & \multirow{2}{*}{ Collection Method } & \multicolumn{2}{|c|}{ Skin Delivery } & \multirow{2}{*}{ Ref } \\
\hline & & & & & & & Scalp Surface Delivery & Follicular Delivery & \\
\hline $\begin{array}{l}\text { Ultra--high-performance liquid } \\
\text { chromatography-tandem mass spectrometry } \\
\text { (UHPLC-MS/MS) }\end{array}$ & Human scalp in vivo & ZnPT 1\%Climbazole 0.5\% shampoo & & & $1 \mathrm{ng} / \mathrm{mL}$ & $\begin{array}{c}\text { Cyanoacrylate glue biopsy } \\
\text { with in-house cutting device } \\
\text { to isolate follicle head }\end{array}$ & $2770 \pm 2540 \mathrm{ng} / \mathrm{cm}^{2}$ & $11 \pm 9 \mathrm{ng} / \mathrm{cm}^{2}$ & {$[128,145]$} \\
\hline \multirow{3}{*}{$\begin{array}{l}\text { High performance liquid chromatography } \\
\text { tandem mass spectrometry (HPLC-MS/MS) }\end{array}$} & \multirow{3}{*}{ Human scalp in vivo } & \multirow{3}{*}{ 1\% ZnPT shampoo } & \multirow{3}{*}{\multicolumn{2}{|c|}{ Not stated }} & \multirow{3}{*}{$1.0 \mathrm{\mu g} / \mathrm{mL}$} & Hair pluck & & $0.6 \pm 0.053 \mathrm{ng} /$ follicle & \multirow{3}{*}{115,141} \\
\hline & & & & & & Cyanoacrylate glue biopsy & - & $22.5 \pm 3.6 \mathrm{ng} /$ /follicle & \\
\hline & & & & & & Scrub solution extraction & & & \\
\hline \multirow{2}{*}{ X-ray fluorescence spectroscopy (XRF) } & \multirow{2}{*}{ Artificial Vitroskin ${ }^{T M}$} & ZnPT 1\% shampoo & \multirow{2}{*}{$100 \mu \mathrm{L} / \mathrm{cm}^{2}$} & \multirow{2}{*}{$30 \mathrm{sec}$} & \multirow{2}{*}{ Not reported } & \multirow{2}{*}{ Whole skin processing } & 11,100 & $\mathrm{~g} / \mathrm{cm}^{2}$ & \multirow{2}{*}{ [142] } \\
\hline & & ZnPT 1\% Climbazole 0.5\% shampoo & & & & & 14.83 & $\mathrm{~g} / \mathrm{cm} 2$ & \\
\hline \multirow{6}{*}{$\begin{array}{l}{ }^{14} \mathrm{C} \mid Z n P T \\
\begin{array}{l}\text { radiolabelling and scintillation } \\
\text { counting }\end{array}\end{array}$} & \multirow[b]{2}{*}{$\begin{array}{l}\text { Rat skin split thickness ex } \\
\text { vivo }\end{array}$} & $\begin{array}{l}\text { 1\% aqueous ZnPT in CMC \& } \\
\text { Darvan }\end{array}$ & \multirow[t]{2}{*}{$10 \mu \mathrm{L} / \mathrm{cm}^{2}$} & \multirow[t]{2}{*}{$24 \mathrm{~h}$} & \multirow[t]{2}{*}{$3.09 \mathrm{mCi} / \mathrm{mmol}$} & \multirow[t]{2}{*}{$\begin{array}{l}\text { Tape stripping } \\
\text { (20 times) }\end{array}$} & \multicolumn{2}{|c|}{$1.55 \mathrm{ug} / \mathrm{cm}^{2}$} & \multirow[t]{2}{*}{ [12] } \\
\hline & & $\begin{array}{l}\text { 48\% aqueous ZnPT in CMC \& } \\
\text { Darvan }\end{array}$ & & & & & \multicolumn{2}{|c|}{$48.94 \mathrm{ug} / \mathrm{cm}^{2}$} & \\
\hline & \multirow{2}{*}{ Monkey scalp in vivo } & \multirow{2}{*}{$0.1 \%$ ZnPT in $0.1 \%$ surfactant } & \multirow{2}{*}{$40 \mu \mathrm{L} / \mathrm{cm}^{2}$} & $3 \mathrm{~h}$ & \multirow{2}{*}{$60 \mathrm{mCi} / \mathrm{g}$} & $\begin{array}{l}\text { Tape stripping } \\
\text { (15 times) }\end{array}$ & 0.0035 & $0.009 \%)$ & {$[143]$} \\
\hline & & & & $72 \mathrm{~h}$ & & & $0.045 \mathrm{u}$ & $0.115 \%)$ & \\
\hline & & $\begin{array}{l}1 \% \text { ZnPT shampoo }+0.1 \% \text { tonic }(2 \\
\text { applications) }\end{array}$ & & & & & & & \\
\hline & Human scalp in vivo & $\begin{array}{c}2 \% \text { ZnPT shampoo }+0.1 \% \text { tonic }(2 \\
\text { applications) }+0.25 \% \text { tonic }(1 \\
\text { application) }\end{array}$ & $10 \mathrm{~g}$ each application & 4 days & $3.09 \mathrm{mCi} / \mathrm{mmol}$ & $\begin{array}{l}\text { Tape stripping (frequency } \\
\text { not reported) }\end{array}$ & & & [12] \\
\hline $\begin{array}{c}{\left[\mathrm{S}^{35} \mathrm{ZnPT} \text { radiolabelling and scintillation }\right.} \\
\text { counting }\end{array}$ & Human forearm in vivo & 1\% ZnPT shampoo & $200 \mu \mathrm{L} / \mathrm{cm}^{2}$ & $5 \mathrm{~min}$ & $0.6 \mu \mathrm{g} / \mathrm{g}$ & $\begin{array}{l}\text { Radioactivity measured } \\
\text { directly over skin }\end{array}$ & $3 \mu \mathrm{g} / \mathrm{cm}$ & f applied) & [144] \\
\hline
\end{tabular}


Much like imaging studies, radiolabeling was the earliest approach used for quantifying delivery. After application of $\left[{ }^{35} \mathrm{~S}\right]$ labelled $\mathrm{ZnPT}$ to the forearm in human subjects, Geiger counting demonstrated that approximately $1 \%$ of the total applied ZnPT dose remains on the skin after shampoo rinsing [144]. Scintillation counting has been performed with human, rat and monkey skin following tape strip collection to determine the degree of the stratum corneum $\mathrm{ZnPT}$ reservoir, with the amount ranging from $0.0035 \mu \mathrm{g} / \mathrm{cm}^{2}$ $\left(0.1 \% w / v\right.$ formulation on monkey skin) [143] up to $48.94 \mu \mathrm{g} / \mathrm{cm}^{2}(48 \% w / v$ formulation on rat skin) [12] depending on the formulation, skin and number of tape strips removed. Interestingly, using analysis of hair clippings approximately 5-fold more ZnPT was found to deposit on the hair fiber itself [12], with a clinical significance that is unknown and requires further investigation (this perhaps may define a third target site along with the scalp surface and hair follicle).

\section{Toxicity Assessment}

Safety is a concern that must always be balanced with efficacy. To quote the father of toxicology, Paracelsus (1493-1541 AD), 'it is the dose that distinguishes poison from remedy'. In order to understand the safety profile of topical $\mathrm{ZnPT}$ it is important to determine the exposure levels that cause toxicity, from non-lethal adverse effects to death, and then compare these to exposure levels that occur from product use.

ZnPT has a long track record of safe use supported by independent regulatory evaluations such as the European Commission on the Scientific Committee of Consumer Safety [12]. Much of the toxicity data generated by industry is made available through these regulatory safety reports. It is considered safe in rinse-off formulations up to a maximum concentration of $2 \% w / v$ and in leave-on products up to $0.25 \% w / v$. The following section will provide a discussion of the approaches that have been used in assessing safety, including studies investigating local and systemic toxicity.

\subsection{Local Cutaneous Toxicity of ZnPT to Human Skin Epithelia}

$\mathrm{ZnPT}$ has been assessed in both human and animal studies to determine local toxicity. This is distinct from systemic toxicity as it occurs at the site of application. It may manifest in different forms either as an acute or chronic reaction, including allergic and irritant contact dermatitis, photosensitivity, pigmentary changes (hypo- or hyper-pigmentation), hair changes (alopecia or hypertrichosis), drug eruptions (e.g., toxic epidermal necrolysis) or tumor development [146].

Although skin irritation and sensitization can bring about similar skin symptoms (e.g., erythema and itch), it is important to make a distinction between them, especially for safety assessment. Irritation occurs due to direct contact and does not involve an immune response [147]. It typically involves disruption to the stratum corneum barrier over a period of time as occurs in the case of surfactant-induced irritation [148]. In contrast, sensitization occurs by an immune response and involves both an induction phase, which occurs upon initial contact, and an elicitation phase, which occurs during subsequent contact, generating an immune skin reaction sometimes within minutes of exposure [149].

$\mathrm{ZnPT}$ has been described as, at worst, a mild irritant and 'very weak' sensitizing agent [12]. In vitro studies such as the chorioallantoic membrane irritation (HET-CAM) assay have been performed demonstrating the threshold for slight irritation (in this case vessel hemorrhage) to be $1 \mu \mathrm{M}$ [150]. A limitation of this approach is that it poorly reflects realistic exposure on intact skin. More complex in vitro models exist using reconstructed skin, which have demonstrated a slight reduction in cell viability for exposure to $0.01 \%$ $w / v \mathrm{ZnPT}$, with poor solubility limiting testing at the maximum commercial concentration of $2 \% w / v$ [151]. There is a clear need for in vitro models to better simulate in-use scenarios, particularly in terms of the formulations applied, as excipients are not inert as was once thought.

Human and animal in vivo studies better replicate in-use conditions and are conducted by exposing a defined skin area to the compound, sometimes under an occlusive 
or semi-occlusive patch, and observer grading of the skin response [152]. Bio-engineering tools such as trans-epidermal water loss and laser Doppler may also be employed in assessment [153]. ZnPT irritation testing has been conducted at a range of concentrations (up to $48 \% w / v$ in animals and $10 \% w / v$ in humans) under different patch conditions (open, semi-occlusive, and closed) and exposure times, including repeat insult up to several days. ZnPT demonstrates only mild skin irritation, even under exaggerated conditions [12].

In animal sensitization studies, which involve initial contact and subsequent challenge to simulate the elicitation and induction phases of response [154], ZnPT was deemed not to have any sensitization potential [12]. Unsurprisingly, for a drug so widely used since it was first approved there have been isolated case reports of human sensitivity to ZnPT [155-159]. The occurrence of sensitivity does however remain very low, with a positive patch test rate ranging from $0.002 \%$ (3 individuals out of 1652) [155] to $1.2 \%$ (2 individuals out of 171) [156]. In those who have suspected sensitization, testing using sodium pyrithione [160] suggests that the response may be due to the pyrithione moiety rather than the inorganic zinc moiety. The shampoo vehicle itself containing surfactants, preservative and fragrance likely poses a greater risk than the active material per se.

In regard to tumorigenic potential, lifetime studies in rats and mice have been conducted and demonstrate no evidence of carcinogenic potential from dermal doses up to $100 \mathrm{mg} / \mathrm{kg} /$ day [12]. ZnPT has also not been shown to cause pigmentary changes in humans from 2-month daily exposure at $0.2-2.0 \%$ under non-occlusive conditions [12].

Overall, evidence to date provides a strong basis for the safe use $\mathrm{ZnPT}$ in shampoo for treating SD. It is important to consider however that this evidence has focused primarily on detecting overt skin changes after exaggerated exposure for typically several days up to several months. Traditional methods that rely on observer scoring under these conditions are unable to detect subtle alterations due to sub-clinical levels of toxicity that may accumulate over time to cause effect. Sub-clinical toxicity my manifest as cellular changes, including changes in the redox state or induction of heat shock response gene expression. This has led to the description of the 'invisible dermatoses' by Kligman [161]. Emerging data combining advanced approaches to toxicological assessment is providing new insight into the potential of $\mathrm{ZnPT}$ to cause acute cellular zinc toxicity (even in nanomolar concentrations of ZnPT as shown by Lamore [162]) with a translational impact for human safety that is not yet known.

Zinc is essential for cellular health however only within a narrow concentration range, out of which, it becomes cytotoxic [163]. Studies using human keratinocytes demonstrate very high sensitivity to $\mathrm{ZnPT}\left(\mathrm{TD}_{50}=500 \mathrm{nM}\right)$ at concentrations which are 100,000-fold lower than the $2 \%$ maximum level currently approved in shampoo [164]. Data from ex vivo static diffusion cell experiments reveal that viable epidermis and dermis may be exposed to $\mathrm{ZnPT}$ levels within this range $\left(0.75 \mu \mathrm{g} / \mathrm{cm}^{2}\right.$ for human skin) after topical exposure (Table 3) [12,115,128,141-143,145]. It should be noted however that this is based on results from Franz cell studies using $\left[{ }^{14} \mathrm{C}\right]$ $\mathrm{ZnPT}$, which, as a radiolabel for the organic moiety, may not fully predict the levels of $\mathrm{Zn}^{2+}$ implicated in inducing cytotoxicity. While the organic moiety shows greater permeation into the circulation in the rat [165], it is unclear from this data whether dissociation occurs on the skin surface or within the viable skin, which is important for determining $\mathrm{Zn}^{2+}$ exposure.

Our research group has used the labile zinc specific probe, ZinPyr-1, to show the intracellular zinc concentrations increase within keratinocytes in vitro when incubated with ZnPT (Figure 9) [138]. Furthermore, inductively coupled plasma mass spectrometry, expression array analysis and immunohistochemistry in re-constructed skin treated with $\mathrm{ZnPT}(0.1-2 \%)$ shows that keratinocyte toxicity may be mediated by increased influx of intracellular zinc, causing upregulation of heat shock protein, loss of genomic integrity and cellular energy crisis $[162,166]$. The question of whether similar processes occur in human skin has been partly addressed again by our group using synchrotron X-ray fluorescence, demonstrating that zinc concentrations significantly increase in ex vivo viable epidermis up to 3.8-fold after application of commercial $2 \% \mathrm{ZnPT}$ formulation for $24 \mathrm{~h}$ (Figure 9) [138]. 
These results appear to demonstrate dissociation occurring primarily on the skin surface as opposed to the viable epidermis.

Table 3. Exposure of zinc pyrithione to viable skin.

\begin{tabular}{|c|c|c|c|c|c|}
\hline Skin & Formulation & Applied Dose & Viable Skin Delivery & Exposure Time & Ref \\
\hline \multirow{2}{*}{$\begin{array}{l}\text { Ex vivo split thickness } \\
\text { rat skin }\end{array}$} & $\begin{array}{c}\mathrm{ZnPT} 48 \% \text {, Darvan, } \\
\text { carboxymethylcellulose, water }\end{array}$ & \multirow{3}{*}{$10 \mu \mathrm{L} / \mathrm{cm}^{2}$} & $118.64 \mu \mathrm{g} / \mathrm{cm}^{2}$ & \multirow{3}{*}{$8 \mathrm{~h}$} & \multirow{3}{*}{ [12] } \\
\hline & \multirow{2}{*}{$\begin{array}{c}\mathrm{ZnPT} 1 \% \text {, Darvan, } \\
\text { carboxymethylcellulose, water }\end{array}$} & & $6.68 \mu \mathrm{g} / \mathrm{cm}^{2}$ & & \\
\hline $\begin{array}{l}\text { Ex vivo split thickness } \\
\text { human skin }\end{array}$ & & & $0.75 \mu \mathrm{g} / \mathrm{cm}^{2}$ & & \\
\hline \multirow{2}{*}{$\begin{array}{l}\text { In vivo monkey scalp } \\
\text { skin }\end{array}$} & \multirow{2}{*}{$\begin{array}{l}\text { 0.1\% ZnPT suspension with surfactant } \\
\text { (triethanolamine alkyl sulfate) }\end{array}$} & \multirow{2}{*}{$0.4 \mathrm{~mL} / 10 \mathrm{~cm}^{2}$} & $0.085 \%\left(0.47 \mu \mathrm{g} / \mathrm{cm}^{2}\right)$ & $3 \mathrm{~h}$ & \multirow{2}{*}{ [143] } \\
\hline & & & $0.090 \%\left(0.5 \mu \mathrm{g} / \mathrm{cm}^{2}\right)$ & $72 \mathrm{~h}$ & \\
\hline
\end{tabular}

Viable skin delivery $=$ epidermis (after stratum corneum removal with tape stripping) + dermis.

Overall, results suggest that $\mathrm{ZnPT}$ has the capability of over-riding the keratinocyte zinc homeostatic system. Further work is needed to determine whether hallmarks for cytotoxicity occur in human skin after application in realistic conditions and, if so, what the implications are for long-term exposure. This will require both gene and protein expression analysis as well as zinc concentration mapping from biopsies of human skin after such exposure. The extent to which $\mathrm{Zn}^{2+}$ can permeate into the underlying skin may be the key factor in regulating potential toxicity from this route. Further work should therefore also explore the sensitivities of different skin cells such as melanocytes or stem cell populations from the hair follicle bulge region to these effects.

\subsection{Systemic Toxicity}

Administration of $\mathrm{ZnPT}$ to different animal species (e.g., rat, mouse, dog and monkey) via different routes (oral, dermal, inhalation, peritoneal and intravenous) have been performed to establish toxic dose thresholds, i.e., the minimal dose that causes toxic effects. ZnPT toxicity is highly dependent on administration route. Inhalational and intravenous administration has the lowest threshold for toxicity, followed by intraperitoneal and oral administration [12]. Systemic effects range from emesis (oral administration in dog) [12], general cholinergic symptoms (intravenous administration in dog and monkey) [167], limb muscle weakness and lung swelling (inhalational administration in rat) to death $[12,168,169]$. Importantly, when ZnPT is administered via the skin in acute doses these symptoms do not occur $[144,170]$. The only acute symptoms reported are 'slight temporary depression' for doses on the order of $10-20 \mathrm{~g} / \mathrm{kg}$ applied to abraded skin of restrained rabbits [144].

The threshold for toxic effects is lowered and the pattern of systemic effects is altered when $\mathrm{ZnPT}$ is provided in repeated doses over 2-13 weeks. Systemic symptoms include haematological changes and hind limb muscle atrophy or paralysis $[12,144,171]$. Hind limb functional effects were reversible, however electrophysiological dysfunction was still detectable [172]. Atrophy is reportedly due to muscle disuse, secondary to neurological effects $[173,174]$, specifically involving peripheral axonopathy which in vitro studies indicate may be mediated by neuronal calcium influx $[175,176]$.

The occurrence of hind limb weakness has been used as the critical effect for threshold exposure values in safety assessment, although the relevance of this to human toxicity is not known. A lethal topical dose has been reported as $1000-2000 \mathrm{mg} / \mathrm{kg}$ when applied 5 days per week for 90 days [12]. At lower doses of $100 \mathrm{mg} / \mathrm{kg}$ over 2 weeks hind limb weakness and local irritation occurs. For chronic dosing at $5 \mathrm{mg} / \mathrm{kg} /$ day for 80 weeks in rats, only local skin irritation has been reported [12]. 

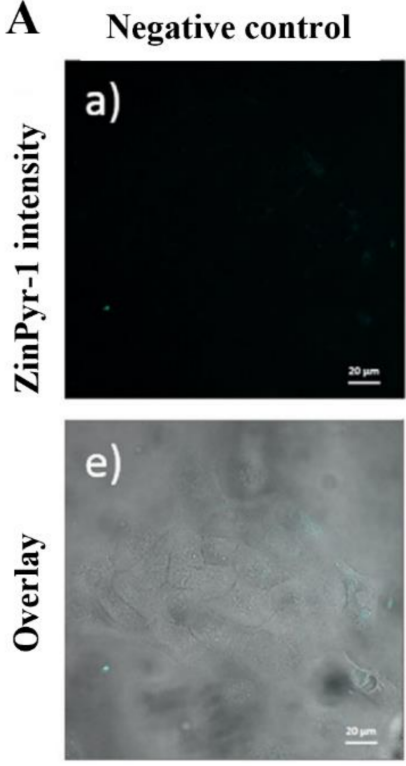

B

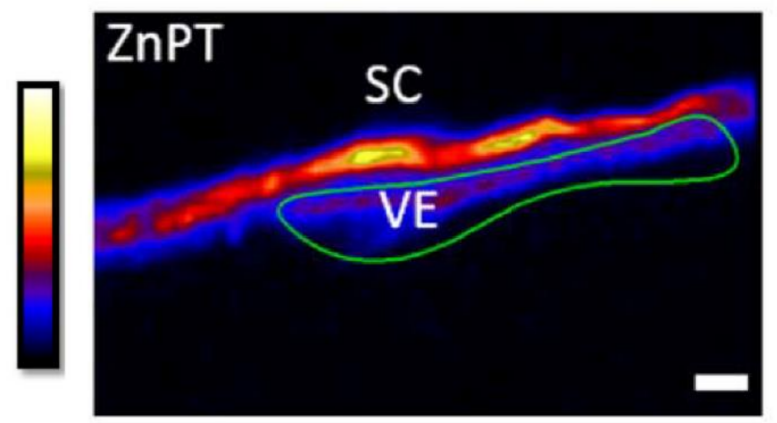

$250 \mathrm{nM} Z \mathrm{ZnPT}$
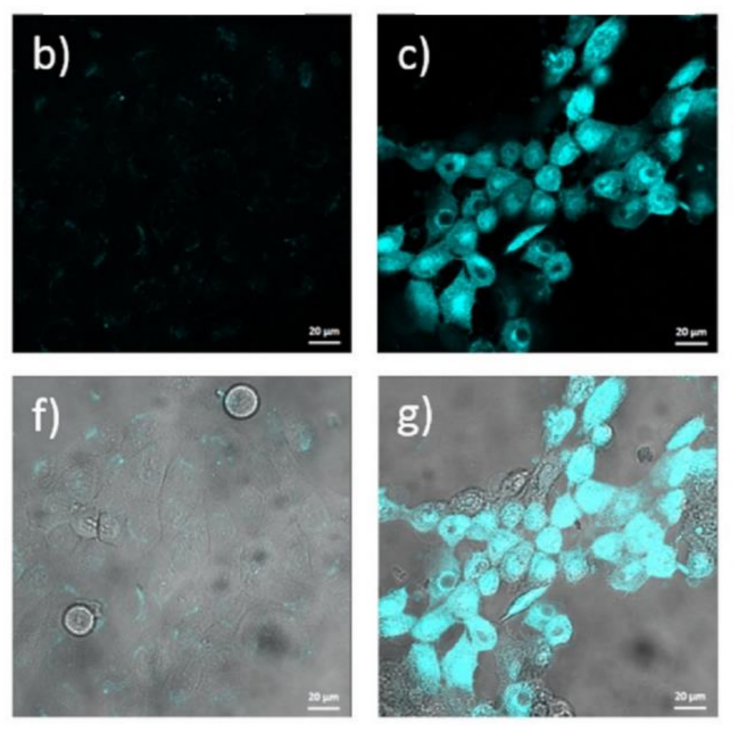

5000 nM ZnPT
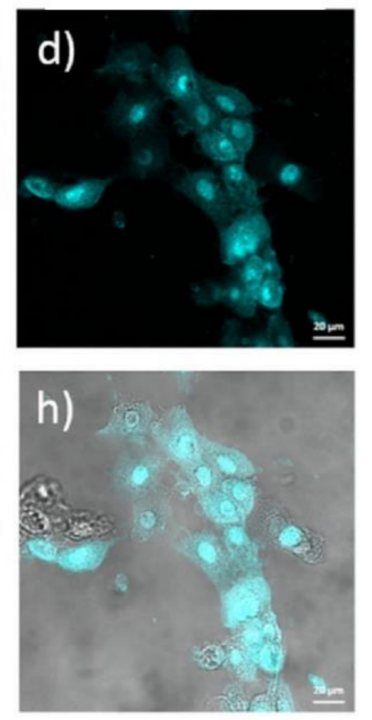

C
Viable epidermis

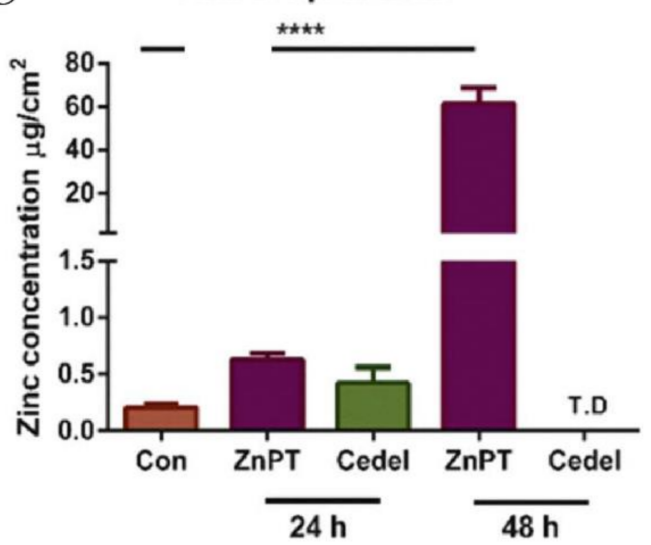

Figure 9. Zinc pyrithione effects on keratinocyte and human skin zinc levels. (A) Co-culturing HaCaT cells with ZnPT increases intracellular labile zinc. Confocal microscopy images of cells stained with ZinPyr-1 (10 $\mu \mathrm{M})$, color coded cyan, after incubation for $24 \mathrm{~h}$ with various concentrations of $\mathrm{ZnPT}(0-5000 \mathrm{nM})$. Images displayed are representative of triplicate images, scale bar represents $20 \mu \mathrm{m}$. (B) Images of zinc distribution with XFM, zinc intensity ascribed an artificial colour range with black being zero concentration and white being the highest concentration. Scale bar represents $20 \mu \mathrm{m}$. (C) Zinc concentrations in the viable epidermis extracted from XRF images of zinc by selecting regions of interest. Holmes et al. (2018), reproduced with permission [138]. The ${ }^{* * *}$ represents $p<0.0001$.

\subsection{Systemic Exposure Following Topical Application}

Radiolabeling studies and more recently studies using liquid chromatography mass spectrometry [177] have been performed to determine the systemic exposure of ZnPT after topical application. The organic (pyrithione) and inorganic (zinc) moieties of ZnPT can be differentially labelled using isotopes of $\left[{ }^{14} \mathrm{C}\right]$ or $\left[{ }^{35} \mathrm{~S}\right]$ and $\left[{ }^{65} \mathrm{Zn}\right]$, respectively. Dosing in rabbits has demonstrated that $\mathrm{ZnPT}$ dissociates in its absorption and distribution after application on the skin [165], with plasma protein binding ranging from 5.9-12.2\% [178]. The organic pyrithione moiety permeates and distributes faster in the major organs compared to the inorganic zinc moiety [165]. This is important because it implicates pyrithione and its metabolites as the primary mediators of systemic toxicity.

Hepatic metabolism and subsequent elimination of pyrithione has been studied in rats, rabbits, monkeys, and dogs after oral dosing $[179,180]$. While several metabolites and intermediates have been identified, the major metabolites include 2-methanesulfonylpyridine (MSP) [179] and S-glucuronide conjugates of 2-pyridinethiol and 2-pyridinethiol-1-oxide 
(SG). Renal and biliary excretion occurs for both, of which the biliary route and faecal excretion occurs at a slower rate due to enterohepatic reabsorption. More than $75 \%$ of the dose is excreted in the urine rapidly within $24 \mathrm{~h}$, primarily as SG [180].

Systemic exposure to ZnPT after topical dosing has been studied in humans and a range of animal species including rat, rabbit, monkey and guinea pig (Table 4) [12,143,165,177,181,182]. Exposure can be estimated in ex vivo Franz cell studies from the amount of ZnPT that permeates into the receptor phase or can also be investigated in vivo with urine or blood serum analysis. For human studies, urine sampling can reliably be used since more than $90 \%$ of the absorbed dose is excreted renally [12]. The amount of $\mathrm{ZnPT}$ exposure depends on a range of factors including the skin type and condition (intact, tape stripped, or artificial sebum supplemented), dosage amount, frequency (single or repeated), formulation (simple aqueous dispersion or as shampoo) and length of exposure. There are important species dependent variations in permeability, with rabbit skin showing the highest permeability, followed by rat and guinea pig [182].

$\mathrm{ZnPT}$ permeation in all cases remains relatively very low, typically representing less than $0.05 \%$ of the initial applied dose. Absorption can be increased by addition of surfactant [143,181], by removal of stratum corneum [143] and for aqueous formulations by the presence of artificial sebum [181]. Studies in both SD and healthy skin show no effect of disease on percutaneous absorption [12]. Increasing the contact time, ZnPT dose, and number of applications does increase exposure, however a steady state is reported to be reached after 4 days daily application [12]. The highest in vivo human exposure of $4.38 \mu \mathrm{g} / \mathrm{kg} /$ day occurs with daily shampoo applications (ZnPT $2 \%$ ) and use of leave-on tonic (ZnPT $0.25 \%)$ for 4 days. This is in close agreement to the human dose level $(4.4 \mu \mathrm{g} / \mathrm{kg})$ projected in earlier studies based on rat exposure data to a $1 \% \mathrm{ZnPT}$ formulation [182]. In both cases, demonstrating that human exposure is well below (on the order of 100-fold lower) than toxicity thresholds reported, for instance $0.5 \mathrm{mg} / \mathrm{kg} /$ day as the no effect level in rats orally fed ZnPT [144].

Recognizing that toxicological exposure studies often represent exaggerated use sceneries (i.e., daily at fixed, typically high doses), computer modelling approaches are making an in-roads to capture realistic ZnPT exposure for human risk assessment. A probabilistic model has reported on the aggregate exposure of ZnPT [183], taking into account information about different product usage patterns of the population (e.g., users that apply different amounts, at different frequencies and from different product sources). In this model, exposure was calculated as $0.01-1.29 \mu \mathrm{g} / \mathrm{kg} /$ day for the top 95th percentile of users, which is again well below threshold for adverse systemic effects. In separate work, physiologically based pharmacokinetic models have been validated for both oral [184] and dermal delivery [185] of ZnPT in the rat, capable of dosimetry predictions for hindlimb weakness. Further research is needed to extrapolate this to humans, however this nevertheless represents an important step forward for the use of computer modelling approaches in safety assessment, which should result in less reliance on animal use in the future. 
Table 4. Human and animal systemic exposure values for zinc pyrithione applied in various formulations.

\begin{tabular}{|c|c|c|c|c|c|}
\hline Skin & Formulation & Applied Dose & $\begin{array}{c}\text { Absorbed Dose } \\
\text { (Cumulative) }\end{array}$ & Exposure Time & Ref \\
\hline \multirow{2}{*}{ Ex vivo split thickness rat skin } & $\begin{array}{c}\text { ZnPT } 48 \% w / v \text {, Darvan, } \\
\text { carboxymethylcellulose, water }\end{array}$ & \multirow{3}{*}{$10 \mu \mathrm{L} / \mathrm{cm}^{2}$} & $\begin{array}{c}0.13 \% \\
\text { (equiv. } 7.01 \mu \mathrm{g} / \mathrm{cm}^{2} \text { ) }\end{array}$ & \multirow{3}{*}{$\begin{array}{l}8 \mathrm{~h} \text {, plus } 16 \mathrm{~h} \text { after removal from } \\
\text { donor chamber }(24 \mathrm{~h} \text { total })\end{array}$} & \multirow{3}{*}{ [12] } \\
\hline & \multirow{2}{*}{$\begin{array}{l}\text { ZnPT } 1 \% w / v \text {, Darvan, } \\
\text { carboxymethylcellulose, water }\end{array}$} & & $1.12 \%$ (equiv. $1.13 \mu \mathrm{g} / \mathrm{cm}^{2}$ ) & & \\
\hline $\begin{array}{l}\text { Ex vivo split thickness human } \\
\text { skin }\end{array}$ & & & $0.02 \%\left(\right.$ equiv $\left.0.02 \mu \mathrm{g} / \mathrm{cm}^{2}\right)$ & & \\
\hline \multirow{3}{*}{$\begin{array}{l}\text { Ex vivo split thickness human } \\
\text { skin }\end{array}$} & $\begin{array}{l}1 \% w / v \mathrm{ZnPT}(1 \% w / v \\
\text { carboxymethylcellulose) }\end{array}$ & \multirow{3}{*}{$5 \mathrm{~mL} / 0.79 \mathrm{~cm}^{2}$} & $0.047 \mu \mathrm{g} / \mathrm{cm}^{2}$ & \multirow{3}{*}{$72 \mathrm{~h}$} & \multirow{3}{*}{ [181] } \\
\hline & $1 \% w / v \mathrm{ZnPT}(1 \% w / v$ body wash $)$ & & $0.19 \mu \mathrm{g} / \mathrm{cm}^{2}$ & & \\
\hline & $1 \% w / v \mathrm{ZnPT}$ (castor oil) & & $0.23 \mu \mathrm{g} / \mathrm{cm}^{2}$ & & \\
\hline \multirow{3}{*}{$\begin{array}{l}\text { Ex vivo split thickness human } \\
\text { skin, } \\
\text { sebum supplemented }\end{array}$} & $\begin{array}{l}1 \% w / v \mathrm{ZnPT}(1 \% w / v \\
\text { carboxymethylcellulose })\end{array}$ & \multirow{3}{*}{$5 \mathrm{~mL} / 0.79 \mathrm{~cm}^{2}$} & $0.14 \mu \mathrm{g} / \mathrm{cm}^{2}$ & \multirow{3}{*}{$72 \mathrm{~h}$} & \multirow{3}{*}{ [181] } \\
\hline & $1 \% w / v \mathrm{ZnPT}(1 \% w / v$ body wash) & & $1.1 \mu \mathrm{g} / \mathrm{cm}^{2}$ & & \\
\hline & $1 \% w / v$ ZnPT (castor oil) & & $0.28 \mu \mathrm{g} / \mathrm{cm}^{2}$ & & \\
\hline \multirow[b]{2}{*}{ In vivo rat skin } & $\begin{array}{c}\text { ZnPT } 48 \% w / v \text {, Darvan, } \\
\text { carboxymethylcellulose, water }\end{array}$ & \multirow[b]{2}{*}{$10 \mu \mathrm{L} / \mathrm{cm}^{2}$} & $0.19 \%$ & \multirow{2}{*}{$8 \mathrm{~h}$, occlusive dressing } & \multirow{2}{*}{ [12] } \\
\hline & $\begin{array}{c}\text { ZnPT } 1 \% w / v, \text { Darvan, } \\
\text { carboxymethylcellulose, water }\end{array}$ & & $0.85 \%$ & & \\
\hline 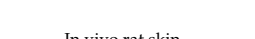 & $5 \% w / v$ ZnPT $+10 \% w / v$ EDTA in shampoo & \multirow{2}{*}{ Not reported } & $1 \mu \mathrm{g}$ & \multirow{2}{*}{$24 \mathrm{~h}$} & \multirow{2}{*}{ [177] } \\
\hline In vivo rat skin & $5 \% w / v$ ZnPT in shampoo & & $1 \mu \mathrm{g}$ & & \\
\hline In vivo rabbit skin & $1 \% w / v$ aqueous suspension & $40 \mathrm{mg} / \mathrm{kg}(4 \mathrm{~mL} / \mathrm{kg})$ & $0.5 \%$ & $8 \mathrm{~h}$ total ( $4 \mathrm{~h}$ before rinsing) & [165] \\
\hline \multirow{4}{*}{ In vivo monkey skin, abdomen } & \multirow{2}{*}{$2 \% w / v \mathrm{ZnPT}$ aqueous suspension } & \multirow{2}{*}{$30 \mathrm{mg} / \mathrm{kg}$} & $0.012-0.039 \%$ & $3 \mathrm{~h}$ & \multirow{7}{*}{ [143] } \\
\hline & & & $0.02 \%$ & 11 days ( 3 applications) & \\
\hline & $2 \% w / v \mathrm{ZnPT}$ suspension with surfactant & & $0.032 \%$ & $3 \mathrm{~h}$ & \\
\hline & (triethanolamine alkyl sulfate) & $30 \mathrm{mg} / \mathrm{kg}$ & $0.2 \%$ & 4 days (3 applications) & \\
\hline $\begin{array}{c}\text { In vivo monkey skin, abdomen } \\
\text { (tape stripped) }\end{array}$ & $\begin{array}{l}2 \% \text { w/v ZnPT suspension with surfactant } \\
\text { (triethanolamine alkyl sulfate) }\end{array}$ & $30 \mathrm{mg} / \mathrm{kg}$ & $0.29 \%$ & $3 \mathrm{~h}$ & \\
\hline \multirow{2}{*}{ In vivo monkey skin, scalp } & \multirow{2}{*}{$\begin{array}{l}0.1 \% w / v \text { ZnPT suspension with surfactant } \\
\text { (triethanolamine alkyl sulfate) }\end{array}$} & \multirow{2}{*}{$\begin{array}{c}0.4 \mathrm{~mL} / 10 \mathrm{~cm}^{2} \\
\left(400 \mu \mathrm{g} / 10 \mathrm{~cm}^{2}\right)\end{array}$} & $1.19-4.39 \%$ & $3 \mathrm{~h}$ & \\
\hline & & & $2.73-3.36 \%$ & $72 \mathrm{~h}$ & \\
\hline In vivo rat skin & & $0.1 \mathrm{~mL} / 7.5 \mathrm{~cm}^{2}$ & $0.17 \mu \mathrm{g} / \mathrm{cm}^{2}$ & $\begin{array}{l}\text { 10-min contact before rinse }(24 \mathrm{~h} \\
\text { monitoring) }\end{array}$ & \multirow{3}{*}{ [182] } \\
\hline In vivo guinea pig skin & $1 \% w / v \mathrm{ZnPT}$ in shampoo base & $0.3 \mathrm{~mL} / 22.5 \mathrm{~cm}^{2}$ & $0.06 \mu \mathrm{g} / \mathrm{cm} 2$ & & \\
\hline In vivo rabbit skin & & $1 \mathrm{~mL} / 75 \mathrm{~cm}^{2}$ & $0.98 \mu \mathrm{g} / \mathrm{cm} 2$ & & \\
\hline \multirow{5}{*}{ In vivo human skin } & ZnPT shampoo $1 \% w / v$ & \multirow{5}{*}{$\begin{array}{l}10 \mathrm{~g} \text { shampoo } \\
4 \mathrm{~g} \text { tonic } \\
\text { per application }\end{array}$} & $1.02 \mu \mathrm{g} / \mathrm{kg} /$ day & 1 day & \multirow{5}{*}{ [12] } \\
\hline & ZnPT shampoo $(1 \% w / v)+$ tonic $(0.1 \% w / v)$ & & $1.39 \mu \mathrm{g} / \mathrm{kg} /$ day & 1 day & \\
\hline & $\mathrm{ZnPT}$ shampoo $1 \% w / v$ & & $2.76 \mu \mathrm{g} / \mathrm{kg} /$ day & 4 days daily application & \\
\hline & ZnPT shampoo $(1 \% w / v)+$ tonic $(0.1 \% w / v)$ & & $3.43 \mu \mathrm{g} / \mathrm{kg} /$ day & 4 days daily application & \\
\hline & ZnPT shampoo $(2 \% w / v)+$ tonic $(0.1 \% w / v)$ & & $4.38 \mu \mathrm{g} / \mathrm{kg} /$ day & 4 days, 2 application & \\
\hline
\end{tabular}

\section{Future Directions and Conclusions}

Observations on seborrheic dermatitis, or at least conditions that mirror its symptomology, have been made since ancient times. This notably includes Celsus and Galen from the 2nd century AD, who postulated on the origins of skin squames [186]. It was not however until the nineteenth century that an association with yeast was made by LouisCharles Malassez [52]. Significant advances have since been made in the development of treatment options in $\mathrm{SD}$, including the formulation of $\mathrm{ZnPT}$ based shampoos. It should also be recognized that $\mathrm{ZnPT}$ is being explored in other applications (Table 5), such as treating atopic dermatitis and fungal infections, which may prove to have significant clinical impact in the future. 
Table 5. Therapeutic re-purposing of zinc pyrithione.

\begin{tabular}{cc}
\hline Use & Evidence \\
\hline ZnPT spray $(0.25 \% w / v)$ used twice daily has been \\
effective in treating psoriatic plaques in one case \\
showing almost complete clearing over 3 weeks \\
with no significant side effects [187]. The classic \\
histopathologic features of psoriasis treated with \\
ZnPT spray $(0.25 \% w / v)$ in a separate case have \\
also been reported to resolve over 2 weeks [188]. A \\
randomised double-blind placebo control study $(n$ \\
$=60)$ found that $0.25 \%$ w $w$ ZnPT emollient cream \\
Psoriasis & used twice daily for 3 months led to a significant \\
& reduction in severity of indurations, erythema and \\
& scaling [189].
\end{tabular}
atopic dermatitis are the same, suggestive of a

Atopic dermatitis and eczema common aetiology [34]. A randomised controlled trial in Chinese children $(n=95)$ showed benefits of a ZnPT ultra-mild body wash with lipids (concentration not reported) on skin microbiome diversity and atopic dermatitis score (SCORAD) when used in conjunction with $0.1 \% w / v$ hydrocortisone butyrate cream [194].
In atopic dermatitis and eczema Malessezia yeast and its metabolites have the potential to cause barrier aggravation [192]. and IgE binding allergens involved in the immune response [193]. Approximately half of the differentially expressed stratum corneum proteins from dandruff and

Results should be interpreted cautiously given the findings from early case studies $[187,188]$ used SkinCap, a commercial product now withdrawn from the market due to reports of contamination with prescription steroid clobestol propionate

[190]. A randomised double-blind study $(n=25)$ found $\mathrm{ZnPT}$ in similar formulation did not enhance the efficacy of clobestol propionate [191]. $\mathrm{ZnPT}$ for psoriasis remains controversial and further evidence is required to determine utility as an adjunct or alternative to conventional medications, which can have important side effects including immune suppression.

ZnPT formulated in body wash may provide adjunctive treatment to corticosteroid use for management of atopic dermatitis and eczema.

$\mathrm{ZnPT}$ may act by altering skin levels of Malassezia yeast or Staphylococcus aureus bacteria, known to be important in aggravating atopic dermatitis [195].

Further evidence of benefit from larger randomised controlled trials is required.

ZnPT exhibits gradual activity against a broad spectrum of gram negative and positive bacteria as well as RNA and DNA viruses [196] for up to three days in an expanded flora test on the forearm [197].

Concentrations up to $0.25 \% w / v \mathrm{ZnPT}$ with alcohol were superior to other combination agents (e.g., iodine, chlorhexidine gluconate and triclosan) for persistence of antimicrobial effects [198].

In mice exposed to ultraviolet-B (UVB) radiation a $1 \% w / v$ ZnPT cream prevented skin thickening and normalized [199] levels of hypoxia-inducible factor- $1 \alpha$, which influences the keratinocyte cell cycle [200].

$\mathrm{ZnPT}$ in antiseptic products has the potential for significant clinical impact, for example by reducing surgical site infections through extended anti-microbial persistence. Efficacy needs to be confirmed in randomised controlled trials and safety needs further evaluation.

ZnPT could be used to prevent UVB-induced photoaging and skin cancer development, potentially as an additive to sunscreens. Further work is needed to demonstrate human efficacy and establish therapeutic doses.

Sub-clinical inflammation of the scalp [201] and Malessezia yeast metabolites [65] are believed to damage the hair shaft and promote hair loss $[202,203]$. In a 6-month clinical trial 1\% $w / v$ ZnPT shampoo caused a significant increase in total visible hair count in males $(n=200)$, with similar performance to $5 \% w / v$ minoxidil topical solution [204].
ZnPT may promote general hair and scalp health [81], for example by providing a source of zinc and reducing inflammation, which could play a role in preventing, delaying or improving symptoms of hair loss.

A question central to assessing therapeutic performance is whether $\mathrm{ZnPT}$ reaches the target sites in SD at appropriate anti-fungal concentrations. Here, we show an average MIC of 10-15 ppm derived from published in vitro broth microdilution studies against Malassezia globosa and restricta. A further goal of targeted delivery with $\mathrm{ZnPT}$ is to maximize deposition and persistence on the scalp surface and within the follicles, while minimizing skin absorption which presents a risk for localized and systemic toxicity. A range of skin imaging methods have demonstrated delivery to the skin surface and uppermost portion 
of the hair follicles. ZnPT faces the unique challenge of achieving this targeted delivery to the scalp in a complex wash-off formulation system. Quantitative dose-depth information would be particularly useful for a more accurate assessment of ZnPT delivery, particularly to the follicles, in addition to data on yeast load in these recessed micro-environments which play an important role in SD pathogenesis.

Further formulation optimization of ZnPT products is likely to focus on improving follicular delivery and may explore strategies that have shown success for the targeting of other compounds into the follicles, including modification of particle shape and the use of functionalized surface coatings $[205,206]$. Targeted delivery, therapeutic efficacy and safety could then be assessed with the complementary techniques that have been examined here.

Author Contributions: Conceptualization, S.E.M., A.M.H. and M.S.R.; methodology, S.E.M., A.M.H.; software, S.E.M., validation, S.E.M., A.M.H. and M.S.R.; formal analysis, S.E.M.; investigation, A.M.H.; resources, M.S.R.; data curation, S.E.M.; writing-original draft preparation, S.E.M.; writingreview and editing, A.M.H. and M.S.R.; visualization, S.E.M.; supervision, A.M.H. and M.S.R.; project administration, A.M.H. and M.S.R.; funding acquisition, M.S.R. All authors have read and agreed to the published version of the manuscript.

Funding: In writing this review, M.S.R. acknowledges the Australian NHMRC (\#1107356, APP1049906), Australian ARC (DP120104792), US FDA (U01FD006700, 1U01FD006496-01, U01FD006522, 1U01FD00522601, 1U01FD005232-01) for the support of his work in this area. S.E.M. acknowledges the support provided by an Australian Government Research Training Program (RTP) Scholarship. A.M.H. acknowledges the support of The Hospital Research Foundation.

Institutional Review Board Statement: Human skin images presented in Figure 8 of this article were acquired according to the guidelines of the Declaration of Helsinki and approved by the Institutional Review Board (CALHN) at The Queen Elizabeth Hospital, ethics approval protocol-2009208.

Informed Consent Statement: Not applicable.

Data Availability Statement: Not applicable.

Conflicts of Interest: This work was undertaken at the Translational Research Institute, Woolloongabba, QLD, and at the Basil Hetzel Institute for Translational Health Research, Woodville, Australia. The Translational Research Institute is supported by a grant from the Australian Government. The authors have no other relevant affiliations or financial involvement with any organization or entity with a financial interest in or financial conflict with the subject matter or materials discussed in the manuscript apart from those disclosed. The views expressed here do not reflect official policies of the Department of Health and Human Services; nor does any mention of trade names, commercial practices, or organization imply endorsement by the United States Government.

\section{References}

1. Saint-Leger, D. Dandruff (pityriasis capitis simplex): Of yeasts and men. In The Science of Haircare; Bouillon, C., Wilkinson, J., Eds.; CRC Press: Boca Raton, FL, USA, 2005; pp. 609-631.

2. Grimalt, R. A Practical Guide to Scalp Disorders. J. Investig. Dermatol. Symp. Proc. 2007, 12, 10-14. [CrossRef] [PubMed]

3. Piérard-Franchimont, C.; Hermanns, J.; Degreef, H.; Piérard, G. From axioms to new insights into dandruff. Dermatology 2000, 200, 93-98. [CrossRef]

4. Chen, S.C.; Yeung, J.; Chren, M.M. Scalpdex: A quality-of-life instrument for scalp dermatitis. Arch. Dermatol. 2002, 138, 803-807. [CrossRef] [PubMed]

5. Godbehere, A.; McDonald, L.; Baines, F.; Sutherland, C.A.M.; Andrews, T.J. A dissociation in judgements of confidence in people with dandruff based on self-reports compared to reports from other observers. Int. J. Cosmet. Sci. 2017, 39, 457-464. [CrossRef] [PubMed]

6. Sampaio, A.L.; Mameri, A.C.; Vargas, T.J.; Ramos-e-Silva, M.; Nunes, A.P.; Carneiro, S.C. Seborrheic dermatitis. An. Bras. Dermatol. 2011, 86, 1061-1071. [CrossRef] [PubMed]

7. Gupta, A.K.; Bluhm, R.; Cooper, E.A.; Summerbell, R.C.; Batra, R. Seborrheic dermatitis. Dermatol. Clin. 2003, 21 , 401-412. [CrossRef]

8. Naldi, L.; Rebora, A. Clinical practice. Seborrheic dermatitis. N. Engl. J. Med. 2009, 360, 387-396. [CrossRef]

9. Schwartz, J.R. Zinc Pyrithione: A Topical Antimicrobial with Complex Pharmaceutics. J. Drugs Dermatol. JDD 2016, 15, 140-144.

10. Proctor and Gamble Company. P\&G's Billion-Dollar Brands: Trusted, Valued, Recognized. Available online: https://www.pg. com/en_US/downloads/media/Fact_Sheets_BB_FA.pdf (accessed on 18 October 2020). 
11. Royal Pharmaceutical Society. Martindale: The Complete Drug Reference. Available online: https://www-medicinescompletecom (accessed on 1 September 2021).

12. Scientific Committee on Consumer Safety. Opinion on Zinc Pyrithione, 18 June 2013. Available online: https:/ / ec.europa.eu/ health/scientific_committees/consumer_safety_en (accessed on 8 February 2021).

13. Lim, H.W.; Collins, S.A.B.; Resneck, J.S., Jr.; Bolognia, J.L.; Hodge, J.A.; Rohrer, T.A.; Van Beek, M.J.; Margolis, D.J.; Sober, A.J.; Weinstock, M.A.; et al. The burden of skin disease in the United States. J. Am. Acad. Dermatol. 2017, 76, 958-972.e952. [CrossRef]

14. Veraldi, S.; Angileri, L.; Barbareschi, M. Seborrheic dermatitis and anti-COVID-19 masks. J. Cosmet. Dermatol. 2020, 19, 2464-2465. [CrossRef] [PubMed]

15. Schwartz, J.R.; Johnson, E.S.; Dawson, T.L. Shampoos for Normal Scalp Hygiene and Dandruff. In Cosmetic Dermatology: Products and Procedures; Draelos, Z.D., Ed.; John Wiley \& Sons: Hoboken, NJ, USA, 2015; pp. 124-131.

16. Food and Drug Administration. Is It a Cosmetic, a Drug, or Both? (Or Is It Soap?). 2012. Available online: https:/ / www.fda.gov/ cosmetics/guidanceregulation/lawsregulations/ucm074201.htm (accessed on 18 October 2020).

17. Bacon, R.A.; Mizoguchi, H.; Schwartz, J.R. Assessing therapeutic effectiveness of scalp treatments for dandruff and seborrheic dermatitis, part 1: A reliable and relevant method based on the adherent scalp flaking score (ASFS). J. Dermatol. Treat. 2012, 25, 232-236. [CrossRef] [PubMed]

18. Kerr, K.; Schwartz, J.R.; Filloon, T.; Fieno, A.; Wehmeyer, K.; Szepietowski, J.C.; Mills, K.J. Scalp stratum corneum histamine levels: Novel sampling method reveals association with itch resolution in dandruff/seborrhoeic dermatitis treatment. Acta Derm.-Venereol. 2011, 91, 404-408.

19. Schwartz, J.R.; Rocchetta, H.; Asawanonda, P.; Luo, F.; Thomas, J.H. Does tachyphylaxis occur in long-term management of scalp seborrheic dermatitis with pyrithione zinc-based treatments? Int. J. Dermatol. 2009, 48, 79-85. [CrossRef]

20. Bonnist, E.Y.M.; Pudney, P.D.A.; Weddell, L.A.; Campbell, J.; Baines, F.L.; Paterson, S.E.; Matheson, J.R. Understanding the dandruff scalp before and after treatment: Anin vivoRaman spectroscopic study. Int. J. Cosmet. Sci. 2014, 36, 347-354. [CrossRef] [PubMed]

21. Collins, L.Z.; Baines, F.L.; Matheson, J.R.; Turner, G.A.; Diao, Y.; Li, Y.; Pi, Y. Sex-related differences in response to zinc pyrithione shampoo vs. non-anti-dandruff shampoo. Int. J. Cosmet. Sci. 2018, 40, 583-588. [CrossRef] [PubMed]

22. Warner, R.R.; Schwartz, J.R.; Boissy, Y.; Dawson, T.L. Dandruff has an altered stratum corneum ultrastructure that is improved with zinc pyrithione shampoo. J. Am. Acad. Dermatol. 2001, 45, 897-903. [CrossRef] [PubMed]

23. Elias, P.M. Epidermal lipids, barrier function, and desquamation. J. Investig. Dermatol. 1983, 80, 44-49. [CrossRef]

24. Matoltsy, A.G.; Parakkal, P.F. Membrane-Coating Granules of Keratinizing Epithelia. J. Cell Biol. 1965, 24, 297-307. [CrossRef]

25. Rawlings, A.V.; Watkinson, A.; Rogers, J.; Mayo, A.-M.; Hope, J.; Scott, I.R. Abnormalities in stratum corneum structure, lipid composition, and desmosome degradation in soap-induced winter xerosis. J. Soc. Cosmet. Chem. 1994, 45, $203-220$.

26. Elias, P.M.; Williams, M.L.; Maloney, M.E.; Bonifas, J.A.; Brown, B.E.; Grayson, S.; Epstein, E.H. Stratum corneum lipids in disorders of cornification. Steroid sulfatase and cholesterol sulfate in normal desquamation and the pathogenesis of recessive X-linked ichthyosis. J. Clin. Investig. 1984, 74, 1414-1421. [CrossRef]

27. Harding, C.R.; Moore, A.E.; Rogers, S.J.; Meldrum, H.; Scott, A.E.; McGlone, F.P. Dandruff: A condition characterized by decreased levels of intercellular lipids in scalp stratum corneum and impaired barrier function. Arch. Dermatol. Res. 2002, 294, 221-230. [CrossRef]

28. Rawlings, A.V. Trends in stratum corneum research and the management of dry skin conditions. Int. J. Cosmet. Sci. 2003, 25, 63-95. [CrossRef]

29. Yoon, J.; Shim, J.; Lim, J.; Park, S.G. Biophysical characteristics of dandruff-affected scalp categorized on the basis of sebum levels. J. Cosmet. Dermatol. 2021, 20, 1002-1008. [CrossRef]

30. Sheu, H.-M.; Chao, S.-C.; Wong, T.-W.; Lee, J.Y.-Y.; Tsai, J.-C. Human skin surface lipid film: An ultrastructural study and interaction with corneocytes and intercellular lipid lamellae of the stratum corneum. Br. J. Dermatol. 1999, 140, 385-391. [CrossRef] [PubMed]

31. Billhimer, W.; Erb, J.; Bacon, R. Shampooing with pyrithione zinc shampoo reduces trans epidermal water loss in scalp of dandruff-involved patients. J. Am. Acad. Dermatol. 2006, 54, AB131.

32. Schwartz, J.; DeAngelis, Y.; Dawson, T.L., Jr. Dandruff and seborrheic dermatitis: A head scratcher. In Practical Modern Hair Science; Evans, T., Wickett, R., Eds.; Allured Books: Chicago, IL, USA, 2012; pp. 389-413.

33. Ackerman, A.B.; Kligman, A.M. Some observations on dandruff. J. Soc. Cosmet. Chem. 1969, $20,81$.

34. Watanabe, S.; Kano, R.; Sato, H.; Nakamura, Y.; Hasegawa, A. The Effects of Malassezia Yeasts on Cytokine Production by Human Keratinocytes. J. Investig. Dermatol. 2001, 116, 769-773. [CrossRef] [PubMed]

35. Perkins, M.A.; Cardin, C.W.; Osterhues, M.A.; Robinson, M. A non-invasive tape absorption method for recovery of inflammatory mediators to differentiate normal from compromised scalp conditions. Skin Res. Technol. 2002, 8, 187-193. [CrossRef]

36. Kerr, K.; Darcy, T.; Henry, J.; Mizoguchi, H.; Schwartz, J.R.; Morrall, S.; Filloon, T.; Wimalasena, R.; Fadayel, G.; Mills, K.J. Epidermal changes associated with symptomatic resolution of dandruff: Biomarkers of scalp health. Int. J. Dermatol. 2010, 50, 102-113. [CrossRef]

37. Cavusoglu, N.; Delattre, C.; Donovan, M.; Bourassa, S.; Droit, A.; El Rawadi, C.; Jourdain, R.; Bernard, D. iTRAQ-based quantitative proteomics of stratum corneum of dandruff scalp reveals new insights into its aetiology and similarities with atopic dermatitis. Arch. Dermatol. Res. 2016, 308, 631-642. [CrossRef] 
38. Candi, E.; Schmidt, R.; Melino, G. The cornified envelope: A model of cell death in the skin. Nat. Rev. Mol. Cell Biol. 2005, 6, 328-340. [CrossRef] [PubMed]

39. Turner, G.A.; Hoptroff, M.; Harding, C.R. Stratum corneum dysfunction in dandruff. Int. J. Cosmet. Sci. 2012, 34, 298-306. [CrossRef] [PubMed]

40. DeAngelis, Y.M.; Gemmer, C.M.; Kaczvinsky, J.R.; Kenneally, D.; Schwartz, J.R.; Dawson, T.L. Three Etiologic Facets of Dandruff and Seborrheic Dermatitis: Malassezia Fungi, Sebaceous Lipids, and Individual Sensitivity. J. Investig. Dermatol. Symp. Proc. 2005, 10, 295-297. [CrossRef] [PubMed]

41. Meray, Y.; Gençalp, D.; Güran, M. Putting It All Together to Understand the Role of Malassezia spp. in Dandruff Etiology. Mycopathologia 2018, 183, 893-903. [CrossRef]

42. Paulino, L.C. New perspectives on dandruff and seborrheic dermatitis: Lessons we learned from bacterial and fungal skin microbiota. Eur. J. Dermatol. EJD 2017, 27, 4-7. [CrossRef]

43. Xu, Z.; Wang, Z.; Yuan, C.; Liu, X.; Yang, F.; Wang, T.; Wang, J.; Manabe, K.; Qin, O.; Wang, X.; et al. Dandruff is associated with the conjoined interactions between host and microorganisms. Sci. Rep. 2016, 6, 24877. [CrossRef]

44. Morand, S.C.; Bertignac, M.; Iltis, A.; Kolder, I.C.R.M.; Pirovano, W.; Jourdain, R.; Clavaud, C. Complete Genome Sequence of Malassezia restricta CBS 7877, an Opportunist Pathogen Involved in Dandruff and Seborrheic Dermatitis. Microbiol. Resour. Announc. 2019, 8, e01543-18. [CrossRef]

45. Wang, L.; Clavaud, C.; Bar-Hen, A.; Cui, M.; Gao, J.; Liu, Y.; Liu, C.; Shibagaki, N.; Guéniche, A.; Jourdain, R.; et al. Characterization of the major bacterial-fungal populations colonizing dandruff scalps in Shanghai, China, shows microbial disequilibrium. Exp. Dermatol. 2015, 24, 398-400. [CrossRef]

46. Soares, R.C.; Camargo-Penna, P.H.; de Moraes, V.C.S.; De Vecchi, R.; Clavaud, C.; Breton, L.; Braz, A.S.K.; Paulino, L.C. Dysbiotic Bacterial and Fungal Communities Not Restricted to Clinically Affected Skin Sites in Dandruff. Front. Cell. Infect. Microbiol. 2016, 6, 157. [CrossRef]

47. Grice, E.A.; Segre, J.A. The skin microbiome. Nat. Rev. Microbiol. 2011, 9, 244-253. [CrossRef]

48. Belkaid, Y.; Tamoutounour, S. The influence of skin microorganisms on cutaneous immunity. Nat. Rev. Immunol. 2016, 16, 353-366. [CrossRef]

49. Buffie, C.G.; Pamer, E.G. Microbiota-mediated colonization resistance against intestinal pathogens. Nat. Rev. Immunol. 2013, 13, 790-801. [CrossRef]

50. Nagy, I.; Pivarcsi, A.; Kis, K.; Koreck, A.; Bodai, L.; McDowell, A.; Seltmann, H.; Patrick, S.; Zouboulis, C.P.D.; Kemény, L. Propionibacterium acnes and lipopolysaccharide induce the expression of antimicrobial peptides and proinflammatory cytokines/chemokines in human sebocytes. Microbes Infect. 2006, 8, 2195-2205. [CrossRef] [PubMed]

51. Chehoud, C.; Rafail, S.; Tyldsley, A.S.; Seykora, J.T.; Lambris, J.D.; Grice, E.A. Complement modulates the cutaneous microbiome and inflammatory milieu. Proc. Natl. Acad. Sci. USA 2013, 110, 15061-15066. [CrossRef]

52. Malassez, R. Note sur les champignon du pityriasis simplex. Arch. Physiol. 1874, 1, 451.

53. McGinley, K.J.; Leyden, J.J.; Marples, R.R.; Path, M.; Kligman, A.M. Quantitative Microbiology of the Scalp in Non-Dandruff, Dandruff, and Seborrheic Dermatitis. J. Investig. Dermatol. 1975, 64, 401-405. [CrossRef] [PubMed]

54. Van Cutsem, J.; Van Gerven, F.; Fransen, J.; Schrooten, P.; Janssen, P. The in vitro antifungal activity of ketoconazole, zinc pyrithione, and selenium sulfide against Pityrosporum and their efficacy as a shampoo in the treatment of experimental pityrosporosis in guinea pigs. J. Am. Acad. Dermatol. 1990, 22, 993-998. [CrossRef]

55. Koga, H.; Munechika, Y.; Matsumoto, H.; Nanjoh, Y.; Harada, K.; Makimura, K.; Tsuboi, R. Guinea pig seborrheic dermatitis model of Malassezia restricta and the utility of luliconazole. Med. Mycol. 2019, 58, 820-826. [CrossRef] [PubMed]

56. Schwartz, J.R.; Bacon, R.A.; Shah, R.; Mizoguchi, H.; Tosti, A. Therapeutic efficacy of anti-dandruff shampoos: A randomized clinical trial comparing products based on potentiated zinc pyrithione and zinc pyrithione/climbazole. Int. J. Cosmet. Sci. 2013, 35, 381-387. [CrossRef] [PubMed]

57. Shuster, S. The aetiology of dandruff and the mode of action of therapeutic agents. Br. J. Dermatol. 1984, 111, 235-242. [CrossRef] [PubMed]

58. Kligman, A.M.; Marples, R.R.; Lantis, L.R.; McGinley, K.J. Appraisal of efficacy of antidandruff formulations. J. Soc. Cosmet. Chem. 1974, 25, 73-91.

59. Marks, R.; Pearse, A.D.; Walker, A.P. The effects of a shampoo containing zinc pyrithione on the control of dandruff. Br. J. Dermatol. 1985, 112, 415-422. [CrossRef]

60. Nenoff, P.; Haustein, U.-F. In vitro susceptibility testing of Pityrosporum ovale against antifungal, antiseborrheic and antipsoriatic agents. J. Eur. Acad. Dermatol. Venereol. 1994, 3, 331-333. [CrossRef]

61. Batra, R.; Boekhout, T.; Guého, E.; Cabañes, F.J.; Dawson, T.; Gupta, A. Malassezia Baillon, emerging clinical yeasts. FEMS Yeast Res. 2005, 5, 1101-1113. [CrossRef] [PubMed]

62. Dawson, T.L. Malassezia: The Forbidden Kingdom Opens. Cell Host Microbe 2019, 25, 345-347. [CrossRef] [PubMed]

63. Tajima, M.; Sugita, T.; Nishikawa, A.; Tsuboi, R. Molecular Analysis of Malassezia Microflora in Seborrheic Dermatitis Patients: Comparison with Other Diseases and Healthy Subjects. J. Investig. Dermatol. 2008, 128, 345-351. [CrossRef]

64. Gemmer, C.M.; DeAngelis, Y.M.; Theelen, B.; Boekhout, T.; Dawson, T.L., Jr. Fast, noninvasive method for molecular detection and differentiation of Malassezia yeast species on human skin and application of the method to dandruff microbiology. J. Clin. Microbiol. 2002, 40, 3350-3357. [CrossRef] 
65. DeAngelis, Y.M.; Saunders, C.W.; Johnstone, K.R.; Reeder, N.L.; Coleman, C.G.; Kaczvinsky, J.R.; Gale, C.; Walter, R.; Mekel, M.; Lacey, M.P.; et al. Isolation and Expression of a Malassezia globosa Lipase Gene, LIP1. J. Investig. Dermatol. 2007, 127, $2138-2146$. [CrossRef]

66. Van Abbe, N.J. The investigation of dandruff. J. Soc. Cosmet. Chem. 1964, 15, 609-630.

67. Troller, J.A. Model system for the investigation of dandruff. J. Soc. Cosmet. Chem. 1971, 22, 187-198.

68. Jourdain, R.; Moga, A.; Vingler, P.; El Rawadi, C.; Pouradier, F.; Souverain, L.; Bastien, P.; Amalric, N.; Breton, L. Exploration of scalp surface lipids reveals squalene peroxide as a potential actor in dandruff condition. Arch. Dermatol. Res. 2016, 308, 153-163. [CrossRef]

69. Gaitanis, G.; Magiatis, P.; Stathopoulou, K.; Bassukas, I.D.; Alexopoulos, E.C.; Velegraki, A.; Skaltsounis, A.-L. AhR Ligands, Malassezin, and Indolo[3,2-b]Carbazole are Selectively Produced by Malassezia furfur Strains Isolated from Seborrheic Dermatitis. J. Investig. Dermatol. 2008, 128, 1620-1625. [CrossRef] [PubMed]

70. Ro, B.I.; Dawson, T.L. The Role of Sebaceous Gland Activity and Scalp Microfloral Metabolism in the Etiology of Seborrheic Dermatitis and Dandruff. J. Investig. Dermatol. Symp. Proc. 2005, 10, 194-197. [CrossRef] [PubMed]

71. Schwartz, J.; Messenger, A.; Tosti, A.; Todd, G.; Hordinsky, M.; Hay, R.; Wang, X.; Zachariae, C.; Kerr, K.; Henry, J.; et al. A Comprehensive Pathophysiology of Dandruff and Seborrheic Dermatitis-Towards a More Precise Definition of Scalp Health. Acta Derm. Venereol. 2013, 93, 131-137. [CrossRef]

72. Wei, S.; Zhang, H.; Yin, Y.; Ma, L.; Li, L.; Dong, Y.; Yi, F. Factor analysis approach unveils the influencing factors of dandruff in the normal teenage population. Dermatol. Ther. 2020, 33, e13690. [CrossRef]

73. Adalsteinsson, J.A.; Kaushik, S.; Muzumdar, S.; Guttman-Yassky, E.; Ungar, J. An update on the microbiology, immunology and genetics of seborrheic dermatitis. Exp. Dermatol. 2020, 29, 481-489. [CrossRef]

74. Leyden, J.J.; McGinley, K.J.; Kligman, A.M. Role of microorganisms in dandruff. Arch. Dermatol. 1976, 112, 333-338. [CrossRef]

75. Xu, J.; Saunders, C.W.; Hu, P.; Grant, R.A.; Boekhout, T.; Kuramae, E.; Kronstad, J.W.; DeAngelis, Y.M.; Reeder, N.L.; Johnstone, K.R.; et al. Dandruff-associated Malassezia genomes reveal convergent and divergent virulence traits shared with plant and human fungal pathogens. Proc. Natl. Acad. Sci. USA 2007, 104, 18730-18735. [CrossRef]

76. James, A.G.; Abraham, K.H.; Cox, D.S.; Moore, A.E.; Pople, J.E. Metabolic analysis of the cutaneous fungi Malassezia globosa and M. restricta for insights on scalp condition and dandruff. Int. J. Cosmet. Sci. 2013, 35, 169-175. [CrossRef]

77. Vijaya Chandra, S.H.; Srinivas, R.; Dawson, T.L.; Common, J.E. Cutaneous Malassezia: Commensal, Pathogen, or Protector? Front. Cell. Infect. Microbiol. 2021, 10. [CrossRef] [PubMed]

78. Karakadze, M.; Hirt, P.; Wikramanayake, T. The genetic basis of seborrhoeic dermatitis: A review. J. Eur. Acad. Dermatol. Venereol. 2017, 32, 529-536. [CrossRef] [PubMed]

79. Wikramanayake, T.C.; Borda, L.J.; Miteva, M.; Paus, R. Seborrheic dermatitis—Looking beyond Malassezia. Exp. Dermatol. 2019, 28, 991-1001. [CrossRef] [PubMed]

80. Skowron, K.; Bauza-Kaszewska, J.; Kraszewska, Z.; Wiktorczyk-Kapischke, N.; Grudlewska-Buda, K.; Kwiecińska-Piróg, J.; Wałecka-Zacharska, E.; Radtke, L.; Gospodarek-Komkowska, E. Human Skin Microbiome: Impact of Intrinsic and Extrinsic Factors on Skin Microbiota. Microorganisms 2021, 9, 543. [CrossRef]

81. Rogers, J.S.; Moore, A.E.; Meldrum, H.; Harding, C.R. Increased scalp skin lipids in response to antidandruff treatment containing zinc pyrithione. Arch. Dermatol. Res. 2003, 295, 127-129. [CrossRef] [PubMed]

82. Mills, K.; Hu, P.; Henry, J.; Tamura, M.; Tiesman, J.; Xu, J. Dandruff/seborrhoeic dermatitis is characterized by an inflammatory genomic signature and possible immune dysfunction: Transcriptional analysis of the condition and treatment effects of zinc pyrithione. Br. J. Dermatol. 2012, 166, 33-40. [CrossRef]

83. Schwartz, J.R.; Henry, J.P.; Kerr, K.M.; Flagler, M.J.; Page, S.H.; Redman-Furey, N. Incubatory environment of the scalp impacts pre-emergent hair to affect post-emergent hair cuticle integrity. J. Cosmet. Dermatol. 2017, 17, 105-111. [CrossRef]

84. Barnett, B.L.; Kretschmar, H.C.; Hartman, F.A. Structural characterization of bis(N-oxopyridine-2-thionato)zinc(II). Inorg. Chem. 1977, 16, 1834-1838. [CrossRef]

85. Schwartz, J.R. Product Pharmacology and Medical Actives in Achieving Therapeutic Benefits. J. Investig. Dermatol. Symp. Proc. 2005, 10, 198-200. [CrossRef]

86. Park, M.; Cho, Y.-J.; Lee, Y.W.; Jung, W.H. Understanding the Mechanism of Action of the Anti-Dandruff Agent Zinc Pyrithione against Malassezia restricta. Sci. Rep. 2018, 8, 1-11. [CrossRef]

87. Pierrel, F.; Cobine, P.A.; Winge, D.R. Metal Ion availability in mitochondria. Biometals 2007, 20, 675-682. [CrossRef]

88. Reeder, N.L.; Kaplan, J.; Xu, J.; Youngquist, R.S.; Wallace, J.; Hu, P.; Juhlin, K.D.; Schwartz, J.R.; Grant, R.A.; Fieno, A.; et al. Zinc Pyrithione Inhibits Yeast Growth through Copper Influx and Inactivation of Iron-Sulfur Proteins. Antimicrob. Agents Chemother. 2011, 55, 5753-5760. [CrossRef]

89. Reeder, N.; Xu, J.; Youngquist, R.; Schwartz, J.; Rust, R.; Saunders, C. The antifungal mechanism of action of zinc pyrithione. Br. J. Dermatol. 2011, 165, 9-12. [CrossRef]

90. Gelling, C.; Dawes, I.W.; Richhardt, N.; Lill, R.; Mühlenhoff, U. Mitochondrial Iba57p Is Required for Fe/S Cluster Formation on Aconitase and Activation of Radical SAM Enzymes. Mol. Cell. Biol. 2008, 28, 1851-1861. [CrossRef]

91. Albert, A.; Rees, C.W.; Tomlinson, A.J.H. The Influence of Chemical Constitution on Anti-bacterial Activity. Part VIII. 2Mercaptopyridine-N-Oxide, and Some General Observations on Metal-binding Agents. Br. J. Exp. Pathol. 1956, 37, 500-511. 
92. Chandler, C.J.; Segel, I.H. Mechanism of the Antimicrobial Action of Pyrithione: Effects on Membrane Transport, ATP Levels, and Protein Synthesis. Antimicrob. Agents Chemother. 1978, 14, 60-68. [CrossRef]

93. Khattar, M.; Salt, W.; Stretton, R. The influence of pyrithione on the growth of micro-organisms. J. Appl. Bacteriol. 1988, 64, 265-272. [CrossRef]

94. Ermolayeva, E.; Sanders, D. Mechanism of pyrithione-induced membrane depolarization in Neurospora crassa. Appl. Environ. Microbiol. 1995, 61, 3385-3390. [CrossRef]

95. Abdel Malek, S.M.; Al-Adham, I.S.; Matalka, K.Z.; Collier, P.J. Pseudomonas aeruginosa PAO1 Resistance to Zinc Pyrithione: Phenotypic Changes Suggest the Involvement of Efflux Pumps. Curr. Microbiol. 2009, 59, 95-100. [CrossRef] [PubMed]

96. NCCLS. Reference Method for Broth Dilution Antifungal Susceptibility Testing of Yeasts. Approved Standard-Second Edition; NCCLS Document M27-A2; NCCLS: Wayne, PA, USA, 2002; ISBN 1-56238-469-4.

97. Onlom, C.; Khanthawong, S.; Waranuch, N.; Ingkaninan, K. In vitro anti-Malassezia activity and potential use in anti-dandruff formulation of Asparagus racemosus. Int. J. Cosmet. Sci. 2014, 36, 74-78. [CrossRef] [PubMed]

98. Leong, C.; Schmid, B.; Buttafuoco, A.; Glatz, M.; Bosshard, P.P. In vitro efficacy of antifungal agents alone and in shampoo formulation against dandruff-associated Malassezia spp. and Staphylococcus spp. Int. J. Cosmet. Sci. 2019, 41, 221-227. [CrossRef]

99. Bulmer, A.C.; Bulmer, G.S. The antifungal action of dandruff shampoos. Mycopathologia 1999, 147, 63-65. [CrossRef]

100. Carrillo-Munoz, A.J.; Rojas, F.; Tur-Tur, C.; de Los Angeles Sosa, M.; Diez, G.O.; Espada, C.M.; Paya, M.J.; Giusiano, G. In vitro antifungal activity of topical and systemic antifungal drugs against Malassezia species. Mycoses 2013, 56, 571-575. [CrossRef]

101. Rukayadi, Y.; Hwang, J.-K. In vitro anti-Malassezia activity of xanthorrhizol isolated from Curcuma xanthorrhiza Roxb. Lett. Appl. Microbiol. 2007, 44, 126-130. [CrossRef]

102. Rukayadi, Y.; Diantini, A.; Lestari, K. Anti Fungal Activity of Methanolic Extract of Usnea SP. Against Malassezia Furfur. Bionatura 2012, 14, 31-37.

103. Squiquera, L.; Plotkin, L.; Mathov, I.; Galimberti, R.; Leoni, J. Analysis of the antifungal activity of ketoconazole, zinc pyrithione, and ciclopirox olamine against Pityrosporum ouale. A diffusion assay for cultures in solid media. J. Eur. Acad. Dermatol. Venereol. 1996, 7, 26-29. [CrossRef]

104. Zieger, M.; Wiegand, C.; Markowetz, A.; Hipler, U. Antifungal activity of zinc pyrithione againstmalasseziaspp. and antiproliferative effect on Hacat-keratinocytesin vitro. Mycoses 2012, 55, 97.

105. Schmidt, A.; Rühl-Hörster, B. In vitro susceptibility of Malassezia furfur. Arzneimittelforschung 1996, 46, 442-444.

106. Roques, C.; Brousse, S.; Panizzutti, C. In vitro antifungal efficacy of ciclopirox olamine alone and associated with zinc pyrithione compared to ketoconazole against Malassezia globosa and Malassezia restricta reference strains. Mycopathologia 2006, 162, 395-400. [CrossRef]

107. Kim, B.J.; Lee, E.C.; Lim, Y.Y.; Kim, D.; Chun, Y.J. Optimal culture condition for antifungal susceptibility tests of Malassezia globose. Kor. J. Med. Mycol. 2009, 14, 182-189.

108. Gerstein, T. Clear zinc pyrithione preparations. J. Soc. Cosmet. Chem. 1972, 23, 99-114.

109. Leong, C.; Wang, J.; Toi, M.J.; Lam, Y.I.; Goh, J.P.; Lee, S.M.; Dawson, T.L. Effect of zinc pyrithione shampoo treatment on skin commensal Malassezia. Med. Mycol. 2021, 59, 210-213. [CrossRef]

110. Torres, M.; de Cock, H.; Celis Ramírez, A.M. In Vitro or In Vivo Models, the Next Frontier for Unraveling Interactions between Malassezia spp. and Hosts. How Much Do We Know? J. Fungi 2020, 6, 155. [CrossRef]

111. Mayser, P.; Argembeaux, H.; Rippke, F. The hair strand test-A new method for testing antifungal effects of antidandruff preparations. J. Cosmet. Sci. 2003, 54, 263-270.

112. Makimura, K.; Tamura, Y.; Kudo, M.; Uchida, K.; Saito, H.; Yamaguchi, H. Species identification and strain typing of Malassezia species stock strains and clinical isolates based on the DNA sequences of nuclear ribosomal internal transcribed spacer 1 regions. J. Med. Microbiol. 2000, 49, 29-35. [CrossRef]

113. Honnavar, P.; Ghosh, A.; Paul, S.; Shankarnarayan, S.; Singh, P.; Dogra, S.; Chakrabarti, A.; Rudramurthy, S. Identification of Malassezia species by MALDI-TOF MS after expansion of database. Diagn. Microbiol. Infect. Dis. 2018, 92, 118-123. [CrossRef]

114. Bailey, P.; Arrowsmith, C.; Darling, K.; Dexter, J.; Eklund, J.; Lane, A.; Little, C.; Murray, B.; Scott, A.; Williams, A.; et al. A double-blind randomized vehicle-controlled clinical trial investigating the effect of ZnPTO dose on the scalp vs. antidandruff efficacy and antimycotic activity. Int. J. Cosmet. Sci. 2003, 25, 183-188. [CrossRef]

115. Schwartz, J.; Shah, R.; Krigbaum, H.; Sacha, J.; Vogt, A.; Blume-Peytavi, U. New insights on dandruff/seborrhoeic dermatitis: The role of the scalp follicular infundibulum in effective treatment strategies. Br. J. Dermatol. 2011, 165, 18-23. [CrossRef]

116. Plewig, G.; Melnik, B.; Chen, W. Pilosebaceous Follicles: Structure, Biochemistry, and Function. In Plewig and Kligman's Acne and Rosacea; Springer Science and Business Media LLC: Berlin/Heidelberg, Germany, 2019; pp. 1-34.

117. Piérard, G.E.; Xhauflaire-Uhoda, E.; Piérard-Franchimont, C. The Key Role of Corneocytes in Pityrosporoses. Dermatology 2005, 212, 23-26. [CrossRef] [PubMed]

118. Piérard-Franchimont, C.; Arrese, J.E.; Piérard, G.E. Immunohistochemical aspects of the link between Malassezia ovalis and seborrheic dermatitis. J. Eur. Acad. Dermatol. Venereol. 1995, 4, 14-19. [CrossRef]

119. Meyer, E.; Otberg, L.; Tietz, N.; Sterry, H.-J.; Lademann, W.J. In vivo imaging of Malassezia yeasts on human skin using confocal laser scanning microscopy. Laser Phys. Lett. 2005, 2, 148-152. [CrossRef]

120. Lousada, M.; Lachnit, T.; Edelkamp, J.; Rouillé, T.; Ajdic, D.; Uchida, Y.; Di Nardo, A.; Bosch, T.; Paus, R. Exploring the human hair follicle microbiome. Br. J. Dermatol. 2021, 184, 802-815. [CrossRef] 
121. Vogt, A.; Mandt, N.; Lademann, J.; Schaefer, H.; Blume-Peytavi, U. Follicular Targeting-A Promising Tool in Selective Dermatotherapy. J. Investig. Dermatol. Symp. Proc. 2005, 10, 252-255. [CrossRef] [PubMed]

122. Vogt, A.; Blume-Peytavi, U. Biology of the human hair follicle. New knowledge and the clinical significance. Hautarzt 2003, 54, 692-698. [CrossRef] [PubMed]

123. Lange-Asschenfeldt, B.; Marenbach, D.; Lang, C.; Patzelt, A.; Ulrich, M.; Maltusch, A.; Terhorst, D.; Stockfleth, E.; Sterry, W.; Lademann, J. Distribution of Bacteria in the Epidermal Layers and Hair Follicles of the Human Skin. Skin Pharmacol. Physiol. 2011, 24, 305-311. [CrossRef] [PubMed]

124. Vest, B.E.; Krauland, K. Malassezia Furfur; StatPearls: Treasure Island, FL, USA. Available online: https://www.ncbi.nlm.nih.gov / books/NBK553091/ (accessed on 2 September 2021).

125. Guého-Kellermann, E.; Batra, R.; Boekhout, T. Chapter 148-Malassezia Baillon (1889). In The Yeasts, 5th ed.; Kurtzman, C.P., Fell, J.W., Boekhout, T., Eds.; Elsevier: London, UK, 2011; pp. 1807-1832.

126. Rutherford, T.; Black, J.G. The use of autoradiography to study the localization of germicides in skin. Br. J. Dermatol. 1969, 81, 75-87. [CrossRef]

127. Rush, A.K.; Miller, M.A.; Smith, E.D.; Kasting, G.B. A quantitative radioluminographic imaging method for evaluating lateral diffusion rates in skin. J. Control. Release 2015, 216, 1-8. [CrossRef]

128. Chen, G.; Ji, C.; Miao, M.; Yang, K.; Luo, Y.; Hoptroff, M.; Collins, L.Z.; Janssen, H.-G. Ex-vivo measurement of scalp follicular infundibulum delivery of zinc pyrithione and climbazole from an anti-dandruff shampoo. J. Pharm. Biomed. Anal. 2017, 143, 26-31. [CrossRef] [PubMed]

129. Garrett, N.L.; Singh, B.; Jones, A.; Moger, J. Imaging microscopic distribution of antifungal agents in dandruff treatments with stimulated Raman scattering microscopy. J. Biomed. Opt. 2017, 22, 66003. [CrossRef]

130. Chen, G.; Ji, C.; Collins, L.Z.; Hoptroff, M.; Janssen, H.-G. Visualization of zinc pyrithione particles deposited on the scalp from a shampoo by tape-strip sampling and scanning electron microscopy/energy dispersive X-ray spectroscopy measurement. Int. J. Cosmet. Sci. 2018, 40, 530-533. [CrossRef]

131. Sandiford, L.; Holmes, A.M.; Mangion, S.E.; Mohammed, Y.H.; Zvyagin, A.V.; Roberts, M.S. Optical Characterisation of Zinc Pyrithione. Photochem. Photobiol. 2019, 95, 1142-1150. [CrossRef]

132. Roberts, M.S.; Cheruvu, H.S.; Mangion, S.E.; Alinaghi, A.; Benson, H.A.; Mohammad, Y.; Holmes, A.; van der Hoek, J.; Pastore, M.E.; Grice, J. Topical drug delivery: History, percutaneous absorption, and product development. Adv. Drug Deliv. Rev. 2021, 113929. [CrossRef] [PubMed]

133. Caspers, P.J.; Lucassen, G.W.; Wolthuis, R.; Bruining, H.A.; Puppels, G.J. In vitro andin vivo Raman spectroscopy of human skin. Biospectroscopy 1998, 4, S31-S39. [CrossRef]

134. Saar, B.G.; Contreras-Rojas, L.R.; Xie, X.S.; Guy, R.H. Imaging Drug Delivery to Skin with Stimulated Raman Scattering Microscopy. Mol. Pharm. 2011, 8, 969-975. [CrossRef]

135. Freudiger, C.W.; Min, W.; Saar, B.G.; Lu, S.; Holtom, G.R.; He, C.; Tsai, J.C.; Kang, J.X.; Xie, X.S. Label-Free Biomedical Imaging with High Sensitivity by Stimulated Raman Scattering Microscopy. Science 2008, 322, 1857-1861. [CrossRef] [PubMed]

136. Lademann, J.; Richter, H.; Meinke, M.; Sterry, W.; Patzelt, A. Which Skin Model Is the Most Appropriate for the Investigation of Topically Applied Substances into the Hair Follicles? Skin Pharmacol. Physiol. 2010, 23, 47-52. [CrossRef]

137. Becker, W. Fluorescence lifetime imaging-Techniques and applications. J. Microsc. 2012, 247, 119-136. [CrossRef] [PubMed]

138. Holmes, A.M.; Song, Z.; Moghimi, H.R.; Roberts, M.S. Relative Penetration of Zinc Oxide and Zinc Ions into Human Skin after Application of Different Zinc Oxide Formulations. ACS Nano 2016, 10, 1810-1819. [CrossRef]

139. Holmes, A.M.; Kempson, I.M.; Turnbull, T.; Paterson, D.; Roberts, M.S. Penetration of Zinc into Human Skin after Topical Application of Nano Zinc Oxide Used in Commercial Sunscreen Formulations. ACS Appl. Bio Mater. 2020, 3, $3640-3647$. [CrossRef]

140. Holmes, A.; Kempson, I.; Turnbull, T.; Paterson, D.; Roberts, M. Imaging the penetration and distribution of zinc and zinc species after topical application of zinc pyrithione to human skin. Toxicol. Appl. Pharmacol. 2018, 343, 40-47. [CrossRef]

141. Gu, Y.-X.; Wang, Q.-H.; Zhou, Z.-L.; Lv, Q.; Mai, C.-H. Determination of zinc pyrithione in shampoos by HPLC and HPLC-MS/MS J. Cosmet. Sci. 2015, 65, 265-276.

142. Turner, G.; Matheson, J.R.; Li, G.-Z.; Fei, X.-Q.; Zhu, D.; Baines, F.L. Enhanced efficacy and sensory properties of an anti-dandruff shampoo containing zinc pyrithione and climbazole. Int. J. Cosmet. Sci. 2012, 35, 78-83. [CrossRef]

143. Gibson, W.; Calvin, G. Percutaneous absorption of zinc pyridinethione in monkeys. Toxicol. Appl. Pharmacol. 1978, $43,425-437$. [CrossRef]

144. Snyder, F.H.; Buehler, E.V.; Winek, C.L. Safety evalation of zinc 2-pyridinethiol 1-oxide in a shampoo formulation. Toxicol. Appl. Pharmacol. 1965, 7, 425-437. [CrossRef]

145. Chen, G.; Miao, M.; Hoptroff, M.; Fei, X.; Collins, L.Z.; Jones, A.; Janssen, H.-G. Sensitive and simultaneous quantification of zinc pyrithione and climbazole deposition from anti-dandruff shampoos onto human scalp. J. Chromatogr. B 2015, 1003, 22-26. [CrossRef] [PubMed]

146. Valeyrie-Allanore, L.; Sassolas, B.; Roujeau, J.-C. Drug-Induced Skin, Nail and Hair Disorders. Drug Saf. 2007, 30, 1011-1030. [CrossRef] [PubMed]

147. Chew, A.L.; Maibach, H.I. Ten Genotypes of Irritant Contact Dermatitis. In Irritant Dermatitis; Chew, A.L., Maibach, H.I., Eds.; Springer: Berlin/Heidelberg, Germany, 2006; pp. 5-9. [CrossRef] 
148. Agner, T.; Serup, J. Sodium Lauryl Sulphate for Irritant Patch Testing-A Dose-Response Study Using Bioengineering Methods for Determination of Skin Irritation. J. Investig. Dermatol. 1990, 95, 543-547. [CrossRef] [PubMed]

149. Kimber, I.; Basketter, D.A.; Gerberick, G.F.; Dearman, R.J. Allergic contact dermatitis. Int. Immunopharmacol. 2002,2 , $201-211$. [CrossRef]

150. Güner, A.; Ilhan, S. Cytotoxic, genotoxic, oxidative, and irritant effects of zinc pyrithione in vitro. Toxicol. Environ. Chem. 2020, 102, 607-623. [CrossRef]

151. Hwang, J.-H.; Jeong, H.; Jung, Y.-O.; Nam, K.T.; Lim, K.-M. Skin irritation and inhalation toxicity of biocides evaluated with reconstructed human epidermis and airway models. Food Chem. Toxicol. 2021, 150, 112064. [CrossRef]

152. Auletta, C.S. Current in vivo Assays for Cutaneous Toxicity: Local and Systemic Toxicity Testing. Basic Clin. Pharmacol. Toxicol. 2004, 95, 201-208. [CrossRef]

153. Berndt, U.; Elsner, P. Prediction Bioengineering. In Irritant Dermatitis; Chew, A.L., Maibach, H.I., Eds.; Springer: Berlin/Heidelberg, Germany, 2006; pp. 201-203. [CrossRef]

154. Buehler, E.V. Delayed Contact Hypersensitivity in the Guinea Pig. Arch. Dermatol. 1965, 91, 171-177. [CrossRef]

155. Brandrup, F.; Menné, T. Zinc pyrithione (Zinc Omadine) allergy. Contact Dermat. 1985, 12, 50. [CrossRef]

156. Pérez, R.G.; Aguirre, A.; Ratón, J.A.; Eizaguirre, X.; Díaz-Pérez, J.L. Positive patch tests to zinc pyrithione. Contact Dermat. 1995, 32, 118-119. [CrossRef]

157. Goh, C.L.; Lim, K.B. Allergic contact dermatitis to zinc pyrithione. Contact Dermat. 1984, 11, 120. [CrossRef] [PubMed]

158. Muston, H.L.; Messenger, A.G.; Byrne, J.H. Contact dermatitis from zinc pyrithione, an antidandruff agent. Contact Dermat. 1979, 5, 276-277. [CrossRef] [PubMed]

159. Pereira, F.; Fernandes, C.; Dias, M.; Lacerda, M.H. Allergic contact dermatitis from zinc pyrithione. Contact Dermat. 1995, $33,131$. [CrossRef]

160. Isaksson, M. Delayed diagnosis of occupational contact dermatitis from sodium pyrithione in a metalworking fluid. Contact Dermat. 2002, 47, 248-249. [CrossRef]

161. Kligman, A.M. The Invisible Dermatoses. Arch. Dermatol. 1991, 127, 1375-1382. [CrossRef]

162. Lamore, S.D.; Cabello, C.M.; Wondrak, G.T. The topical antimicrobial zinc pyrithione is a heat shock response inducer that causes DNA damage and PARP-dependent energy crisis in human skin cells. Cell Stress Chaperones 2010, 15, 309-322. [CrossRef]

163. Bozym, A.; Chimienti, R.; Giblin, F.; Gross, L.J.; Korichneva, G.W.; Li, I.; Libert, Y.; Maret, S.; Parviz, W.; Frederickson, M.C.J.; et al. Free zinc ions outside a narrow concentration range are toxic to a variety of cells in vitro. Exp. Biol. Med. 2010, 235, 741-750. [CrossRef] [PubMed]

164. Borovanský, J.; Riley, P.A. Cytotoxicity of zinc in vitro. Chem. Interact. 1989, 69, 279-291. [CrossRef]

165. Klaassen, C.D. Absorption, distribution, and excretion of zinc pyridinethione in rabbits. Toxicol. Appl. Pharmacol. 1976, 35, 581-587. [CrossRef]

166. Lamore, S.D.; Wondrak, G.T. Zinc pyrithione impairs zinc homeostasis and upregulates stress response gene expression in reconstructed human epidermis. Biometals 2011, 24, 875-890. [CrossRef] [PubMed]

167. Winek, C.; Buehler, E. Intravenous toxicity of zinc pyridinethione and several zinc salts. Toxicol. Appl. Pharmacol. 1966, 9, 269-273. [CrossRef]

168. Cummins, L.M.; Kimura, E.T. Safety evaluation of selenium sulfide antidandruff shampoos. Toxicol. Appl. Pharmacol. 1971, 20, 89-96. [CrossRef]

169. Segawa, T.; Takagi, M. “Bis (1-hydroxy-2(1 H)-pyridinethionato) zinc (ZPT): Pharmacological properties of bis (1-hydroxy-2(1 H)-pyridinethionato) zinc (ZPT)". Oyo Yakuri 1970, 4, 883-890.

170. Wedig, J.; Kennedy, G.L., Jr.; Jenkins, D.; Henderson, R.; Keplinger, M.G.K. Teratologic evaluation of dermally applied zinc pyrithione on swine. Toxicol. Appl. Pharmacol. 1976, 36, 255-259. [CrossRef]

171. Zinkpyrithion. Available online: http:/ / onlinelibrary.wiley.com/doi/10.1002/3527600418.mb1346341d0052/pdf (accessed on 18 October 2020).

172. Ross, J.; Lawhorn, G. ZPT-related distal axonopathy: Behavioral and electrophysiologic correlates in rats. Neurotoxicol. Teratol. 1990, 12, 153-159. [CrossRef]

173. Snyder, D.; Gralla, E.; Coleman, G.; Wedig, J. Preliminary neurological evaluation of generalized weakness in zinc pyrithionetreated rats. Food Cosmet. Toxicol. 1977, 15, 43-47. [CrossRef]

174. DeJesus, C.P.V.; Towfighi, J.; Snyder, D.R. Sural nerve conduction study in the rat: A new technique for studying experimental neuropathies. Muscle Nerve 1978, 1, 162-167. [CrossRef]

175. Knox, R.J.; Magoski, N.S.; Wing, D.; Barbee, S.J.; Kaczmarek, L.K. Activation of a calcium entry pathway by sodium pyrithione in the bag cell neurons of Aplysia. J. Neurobiol. 2004, 60, 411-423. [CrossRef]

176. Knox, R.J.; Keen, K.L.; Luchansky, L.; Terasawa, E.; Freyer, H.; Barbee, S.J.; Kaczmarek, L.K. Comparative effects of sodium pyrithione evoked intracellular calcium elevation in rodent and primate ventral horn motor neurons. Biochem. Biophys. Res. Commun. 2008, 366, 48-53. [CrossRef]

177. Jung, D.S.; Jung, G.H.; Lee, E.H.; Park, H.R.; Kim, J.H.; Kim, K.-B.; Kim, H.R.; Kim, H.G. Effect of Combined Exposure to EDTA and Zinc Pyrithione on Pyrithione Absorption in Rats. Toxicol. Res. 2019, 35, 155-160. [CrossRef]

178. Wedig, J.; Wentworth, R.; Gallo, M.; Babish, J.; Henion, J. Disposition of zinc pyrithione in the rat. Food Cosmet. Toxicol. 1978, 16, 553-561. [CrossRef] 
179. Gibson, W.; Jeffcoat, A.; Turan, T.S.; Wendt, R.H.; Hughes, P.F.; Twine, M.E. Zinc pyridinethione: Serum metabolites of zinc pyridinethione in rabbits, rats, monkeys, and dogs after oral dosing. Toxicol. Appl. Pharmacol. 1982, 62, 237-250. [CrossRef]

180. Jeffcoat, A.; Gibson, W.; Rodriguez, P.A.; Turan, T.S.; Hughes, P.F.; Twine, M.E. Zinc pyridinethione: Urinary metabolites of zinc pyridinethione in rabbits, rats, monkeys, and dogs after oral dosing. Toxicol. Appl. Pharmacol. 1980, 56, 141-154. [CrossRef]

181. Rush, A.K.; Nash, J.; Iii, E.D.S.; Kasting, G.B. Formulation and Artificial Sebum Effects on the Percutaneous Absorption of Zinc Pyrithione through Excised Human Skin. Skin Pharmacol. Physiol. 2019, 32, 224-234. [CrossRef]

182. Howes, D.; Black, J. Comparative percutaneous absorption of pyrithiones. Toxicology 1975, 5, 209-220. [CrossRef]

183. Tozer, S.A.; Kelly, S.; O’Mahony, C.; Daly, E.; Nash, J. Aggregate exposure modelling of zinc pyrithione in rinse-off personal cleansing products using a person-orientated approach with market share refinement. Food Chem. Toxicol. 2015, 83, 103-110. [CrossRef]

184. Diamond, G.L.; Skoulis, N.P.; Jeffcoat, A.R.; Nash, J.F. A physiologically based pharmacokinetic model for the broad-spectrum antimicrobial zinc pyrithione: I. Development and verification. J. Toxicol. Environ. Health Part A 2017, 80, 69-90. [CrossRef]

185. Diamond, G.L.; Skoulis, N.P.; Jeffcoat, A.R.; Nash, J.F. A Physiological-Based Pharmacokinetic Model For The Broad Spectrum Antimicrobial Zinc Pyrithione: II. Dermal Absorption and Dosimetry in The Rat. J. Toxicol. Environ. Health Part A 2021, 84, 609-631. [CrossRef]

186. Saint-Léger, D. The history of dandruff and dandruff in history. A homage to Raymond Sabouraud. Ann. Dermatol. Vénéréol. 1990, 117, 23-27. [PubMed]

187. Crutchfield, C.E., 3rd; Lewis, E.J.; Zelickson, B.D. The highly effective use of topical zinc pyrithione in the treatment of psoriasis: A case report. Dermatol. Online J. 1997, 3, 3.

188. Rowlands, C.G.; Danby, F.W. Histopathology of Psoriasis Treated with Zinc Pyrithione. Am. J. Dermatopathol. 2000, 22, 272-276. [CrossRef]

189. Sadeghian, G.; Ziaei, H.; Nilforoushzadeh, M.A. Treatment of localized psoriasis with a topical formulation of zinc pyrithione. Acta Dermatovenerol. Alp. Pannonica Adriat. 2011, 20, 187-190. [PubMed]

190. Maddin, S. The Skin-Cap Story. Available online: https://www.skintherapyletter.com/dermatology/the-skin-cap-story/ (accessed on 2 September 2021).

191. Housman, T.S.; Keil, K.A.; Mellen, B.G.; McCarty, M.A.; Fleischer, A.B.; Feldman, S. The use of $0.25 \%$ zinc pyrithione spray does not enhance the efficacy of clobetasol propionate $0.05 \%$ foam in the treatment of psoriasis. J. Am. Acad. Dermatol. 2003, 49, 79-82. [CrossRef] [PubMed]

192. Gaitanis, G.; Magiatis, P.; Hantschke, M.; Bassukas, I.D.; Velegraki, A. The Malassezia genus in skin and systemic diseases. Clin Microbiol. Rev. 2012, 25, 106-141. [CrossRef]

193. Ishibashi, Y.; Kato, H.; Asahi, Y.; Sugita, T.; Nishikawa, A. Identification of the major allergen of Malassezia globosa relevant for atopic dermatitis. J. Dermatol. Sci. 2009, 55, 185-192. [CrossRef]

194. Xu, Z.; Liu, X.; Niu, Y.; Shen, C.; Heminger, K.; Moulton, L.; Yu, A.; Allen, T.; Zhang, L.; Yue, F.; et al. Skin benefits of moisturising body wash formulas for children with atopic dermatitis: A randomised controlled clinical study in China. Australas. J. Dermatol. 2020, 61, e54-e59. [CrossRef]

195. Breuer, K.; Häussler, S.; Kapp, A.; Werfel, T. Staphylococcus aureus: Colonizing features and influence of an antibacterial treatment in adults with atopic dermatitis. Br. J. Dermatol. 2002, 147, 55-61. [CrossRef]

196. Guthery, E.; Seal, L.A.; Anderson, E.L. Zinc pyrithione in alcohol-based products for skin antisepsis: Persistence of antimicrobial effects. Am. J. Infect. Control. 2005, 33, 15-22. [CrossRef] [PubMed]

197. Leyden, J.J.; Stewart, R.; Kligman, A.M. Updated in vivo Methods for Evaluating Topical Antimicrobial Agents on Human Skin. J. Investig. Dermatol. 1979, 72, 165-170. [CrossRef]

198. Hobson, D.; Woller, W.; Anderson, L.; Guthery, E. Development and evaluation of a new alcohol-based surgical hand scrub formulation with persistent antimicrobial characteristics and brushless application. Am. J. Infect. Control. 1998, 26, 507-512. [CrossRef]

199. Cho, Y.-S.; Lee, K.-H.; Park, J.-W. Pyrithione-zinc Prevents UVB-induced Epidermal Hyperplasia by Inducing HIF-1 $\alpha$. Korean J. Physiol. Pharmacol. 2010, 14, 91-97. [CrossRef] [PubMed]

200. Cho, Y.-S.; Bae, J.-M.; Chun, Y.-S.; Chung, J.-H.; Jeon, Y.-K.; Kim, I.-S.; Kim, M.-S.; Park, J.-W. HIF-1 $\alpha$ controls keratinocyte proliferation by up-regulating p21(WAF1/Cip1). Biochim. Biophys. Acta (BBA)—Mol. Cell Res. 2008, 1783, 323-333. [CrossRef]

201. Piérard, G.; Piérard-Franchimont, C.; Nikkels-Tassoudji, N.; Nikkels, A.; Léger, D.S. Improvement in the inflammatory aspect of androgenetic alopecia. A pilot study with an antimicrobial lotion. J. Dermatol. Treat. 1996, 7, 153-157. [CrossRef]

202. Piérard-Franchimont, C.; Xhauflaire-Uhoda, E.; Loussouarn, G.; Saint Léger, D.; Piérard, G.E. Dandruff-associated smouldering alopecia: A chronobiological assessment over 5 years. Clin. Exp. Dermatol. 2006, 31, 23-26. [CrossRef] [PubMed]

203. Piérard-Franchimont, C.; De Doncker, P.; Cauwenbergh, G.; Piérard, G. Ketoconazole Shampoo: Effect of Long-Term Use in Androgenic Alopecia. Dermatology 1998, 196, 474-477. [CrossRef]

204. Berger, R.; Fu, J.; Smiles, K.; Turner, C.; Schnell, B.; Werchowski, K.; Lammers, K. The effects of minoxidil, $1 \%$ pyrithione zinc and a combination of both on hair density: A randomized controlled trial. Br. J. Dermatol. 2003, 149, 354-362. [CrossRef]

205. Knorr, F.; Lademann, J.; Patzelt, A.; Sterry, W.; Blume-Peytavi, U.; Vogt, A. Follicular transport route-Research progress and future perspectives. Eur. J. Pharm. Biopharm. 2009, 71, 173-180. [CrossRef]

206. Patzelt, A.; Lademann, J. Recent advances in follicular drug delivery of nanoparticles. Expert Opin. Drug Deliv. 2020, 17, 49-60. [CrossRef] [PubMed] 